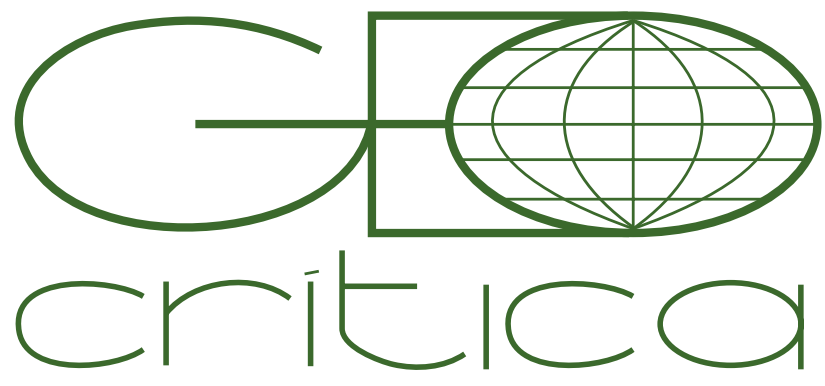

\section{Scripta Nova}

Revista Electrónica de Geografía y Ciencias Sociales Universidad de Barcelona

\title{
NUEVAS METODOLOGÍAS PARA EL ESTUDIO DE LA MOVILIDAD HABITUAL: EL USO DE LOS REGISTROS ADMINISTRATIVOS EN LA MOVILIDAD POR MOTIVOS DE ESTUDIO EN CATALUNYA
}

\author{
Joan Alberich González \\ Departament de Geografia. Universitat Rovira i Virgili \\ joan.alberich@urv.cat \\ Recibido: 18 de febrero de 2014. Aceptado: 2 de octubre de 2014
}

\begin{abstract}
Resumen.Nuevas metodologías para el estudio de la movilidad habitual: el uso de los registros administrativos en la movilidad por motivos de estudio en Catalunya

El cambio en el censo de 2011 ha supuesto la pérdida de información sobre la movilidad habitual, hecho especialmente grave en el caso de Catalunya, donde desde el año 1986 se disponía de una serie homogénea. Para suplir este hecho, desde el año 2011 el Institut d'Estadística de Catalunya realiza la explotación estadística de los registros administrativos, que proporcionan información con carácter anual. El artículo tiene un doble objetivo: por un lado, analizar la validez de esta fuente de información y, por el otro, trazar una breve radiografía de la movilidad reciente por motivo de estudios en Catalunya.
\end{abstract}

Palabras clave: movilidad habitual por estudios, registro administrativo, Catalunya, censo de población, 2011.

\begin{abstract}
New methodologies for the study of the commuting: the use of administrative records in the mobility of the students in Catalonia After the birth of the consumer cooperative in the mid- nineteenth century in Rochdale, this associations spread quickly across Western Europe. In this paper we will analyze how this process was in Spain, in order to put forward some initial results on the following questions: the chronological and geographical development of the consumer cooperative, its ideological orientation, the evolutiand management mechanisms, and the effect these cooperatives had in terms.
\end{abstract}

Key words: commuting by studies, administrative record, Catalonia, population census, 2011. 
El cambio metodológico iniciado con el censo de población de 2001 y que se ha consolidado en la edición correspondiente al año 2011 ha implicado, entre otras consecuencias, la pérdida de información sobre la movilidad habitual por motivos de estudio y trabajo. El principal problema radica en el hecho que la información sobre esta temática se recoge en la parte del censo elaborada a partir de una muestra de la población (realizada alrededor del $10 \%$ de la población), de modo que únicamente se dispone de información sobre movilidad para los municipios mayores de 10.000 habitantes. Este hecho es especialmente grave en el caso de Catalunya, donde desde el año 1986 se disponía de una serie relativamente homogénea sobre información del lugar de trabajo o estudio de la población, con un elevado grado de desagregación territorial.

Uno de los motivos que respaldaron y justificaron este cambio metodológico del censo es la teórica posibilidad de obtener esta información a partir del cruce de los datos de varios registros administrativos. Mientras que en el caso de la movilidad por motivos de trabajo aún no se ha hecho ningún adelanto en este sentido, en el de la movilidad por estudios el Institut d'Estadística de Catalunya (IDESCAT) elabora, para el ámbito catalán, desde el año 2011 y con una periodicidad anual, la explotación estadística de los registros de la Secretaria de Universitats i Recerca y del Departament d'Ensenyament de la Generalitat de Catalunya.

Así, el uso de estos registros administrativos ha de permitir conocer, por un lado, la movilidad de la población estudiante no universitaria (población a partir de 3 años matriculada en cursos de educación infantil, primaria, secundaria obligatoria, bachillerato y ciclos formativos) y, por el otro, la de la población que cursa algún tipo de estudio universitario.

El artículo persigue, en consecuencia, un doble objetivo: en primer lugar, analizar y evaluar la validez de estas fuentes de información, con especial hincapié en sus virtudes pero también en sus limitaciones; $y$, por el otro, trazar una breve radiografía de la movilidad por motivo de estudios en Catalunya los últimos años.

\section{La importancia del estudio de la movilidad habitual en geografía}

Una definición comúnmente aceptada de la movilidad es la que la describe como la suma de desplazamientos que hacen los ciudadanos para acceder a los trabajos, a los bienes y servicios necesarios para su quehacer cotidiano. Así, la movilidad por motivo de trabajo o estudio, que algunos autores denominan como movilidad obligada e incluso movilidad ocupacional, es tan sólo una de las diversas movilidades que protagonizan las personas, junto con algunas otras como el estudio, las compras, el ocio, etc., que constituyen lo que comúnmente se ha denominado movilidad no obligada o personal.

1 Ajenjo hace una interesante reflexión sobre estos términos, ya que cuestiona la obligatoriedad de ciertas actividades (el acudir al lugar de trabajo o de estudio), supuestamente esenciales para vivir. Por este motivo, y suscribiendo las palabras de este autor, en el presente trabajo se ha optado por utilizar exclusivamente el término movilidad habitual (para diferenciarse explícitamente de las migraciones) y añadiendo, en este caso, el motivo de dicho movimiento (trabajo, estudios, etc.): Ajenjo, 
Tres elementos, sin embargo, convierten la movilidad habitual por trabajo o estudio en especialmente significativa en el análisis de la movilidad cotidiana global de las personas sobre el territorio: a) se trata de un fenómeno que afecta - al menos de manera potencial- buena parte de la población total, en cuanto que son demandantes todos los individuos que estudian o trabajan; b) la periodicidad y la fidelidad de los flujos, puesto que, a diferencia de otras movilidades de carácter no habitual, los desplazamientos por trabajo o estudio acostumbran a tener una cadencia elevada (mayoritariamente, como mínimo, de un desplazamiento de ida y uno de vuelta cada día) y a tener un mismo destino; y c) la disponibilidad de datos provenientes de los censos y de los padrones de población que permiten realizar, por la dimensión de su muestra (coincidente con el universo), análisis territoriales con un nivel de detalle muy superior. Así, la unidad de análisis obtenido de esta fuente (el municipio o, incluso, inferior) es difícilmente alcanzable a partir de una metodología muestral.

A pesar de que el análisis de la movilidad habitual, entendida como el cruce entre el lugar de residencia y el puesto de trabajo o estudio, es una simplificación que empobrece en demasía la realidad de los desplazamientos - en la medida que a menudo presentan recorridos, frecuencias o encadenamientos con otros desplazamientos y con diferentes motivaciones-, permite descubrir estructuras elementales de articulación de las relaciones cotidianas de la población sobre el territorio en cualquier escala de análisis. Por este motivo, la movilidad por motivos de trabajo o estudio, dadas sus tres características apuntadas anteriormente, se ha usado a menudo en el estudio de las dinámicas territoriales, en el marco general del proceso de expansión de la ciudad sobre el territorio.

La literatura sobre esta temática es muy abundante y únicamente citaremos aquí los principales trabajos que hacen referencia al ámbito catalán. Cronológicamente, una de los primeros trabajos es el de Serra, ${ }^{2}$ en el que se delimita los mercados de trabajo al ámbito metropolitano a partir del número de personas que se desplaza diariamente para ir a trabajar. A partir de aquí se configuran diferentes mapas de la movilidad en función de los movimientos entre municipios cuantificando el grado de interdependencia laboral. En la misma línea hay autores ${ }^{3}$ que han tratado el que se puede denominar como sistemas urbanos diarios a través del análisis de la movilidad obligada en el ámbito de la antigua Corporación Metropolitana de Barcelona. En esa misma línea, Roca ${ }^{4}$ delimita el espacio metropolitano a partir de datos de censos y padrones diferentes, hasta llegar al censo de 1991, de forma que muestra la evolución que ha tenido esta área metropolitana utilizando los criterios de movilidad para definirla. Pero lo que es más interesante no es la metodología, que se repite en muchos trabajos, sino el resumen que hace de las definiciones que otros autores han dado de área metropolitana, la mayoría de las cuales utilizan el concep-

\footnotetext{
2005, p. 19; Ajenjo 2010, p. 13,

2 Serra, 1985.

3 Nunes, 1986.

4 Roca, 1997.
} 
to de movilidad «obligada» para delimitarla, entre las que destacan los trabajos de Esteban Quintana, ${ }^{5}$ Serra, ${ }^{6}$ Esteban Noguera ${ }^{7}$ o Clusa. ${ }^{8}$ Para el resto del territorio catalán, destacan los trabajos de Castañer et al. ${ }^{9}$ para el área de Girona; Alberich ${ }^{10}$ para el Camp de Tarragona y Ganau ${ }^{11}$ para el caso de Lleida.

Sin embargo, muchos de estos trabajos se han centrado en la movilidad habitual por motivos de trabajo, siendo la movilidad por estudios menos analizada, indudablemente porqué afecta, a priori, un menor número de personas, y, en segundo lugar, porqué existe la concepción generalizada que la condición de estudiante es una situación "transitoria», que acostumbra a afectar tan sólo a personas situadas en unas etapas muy concretas de su ciclo de vida (y a pesar que, desde hace algunos años, la formación continua a lo largo de la vida ha ido adquiriendo importancia).

Los trabajos que incluyen la movilidad por estudios se han incrementado ligeramente desde la publicación de los resultados del censo de población de 2001 en el marco de la aparición del concepto de población vinculada, ${ }^{12}$ concepto que aparece como una reinterpretación de la antigua población de hecho y que pretende aproximarse al uso temporal que las poblaciones hacen de un determinado territorio a partir de su movilidad habitual (por trabajo, estudio o segundas residencias) y que, desde el punto de vista de los individuos, puede interpretarse territorialmente en clave de espacios de vida. Uno de los autores que más ha reflexionado de manera teórica sobre este concepto es Módenes, ${ }^{13}$ aunque el uso de la movilidad por motivos de estudio como uno de los componentes de la población vinculada de un territorio ha sido poco frecuente y, muy a menudo, obviada. Como ya apuntaban Roquer y Blay,,$^{14}$ y en la línea argumental seguida por Alberich, ${ }^{15}$ el principal inconveniente recae en el hecho que en el cómputo total de esta población por igual con otras dos movilidades (por trabajo y por segunda residencia), lo que evidentemente no sucede en realidad, por tener las tres movilidades calendarios e intensidades distintos. Por ello, la solución deseable pasaría por ponderar el grado de vinculación de cada colectivo en función del motivo de la movilidad.

Quizás por este motivo, el tratamiento de la movilidad por estudios ha tenido poco tratamiento en la literatura consultada y, en cualquier caso, de manera independiente respecto de la movilidad por motivos de trabajo u otras motivaciones. Un buen ejemplo de ello es el trabajo realizado por Ajenjo et al., ${ }^{16}$ cuyo objetivo es delimitar el espacio de vida de la población española a partir de los datos de movilidad del

5 Esteban Quintana, 1989.

6 Serra, 1991.

7 Esteban Noguera, 1991.

8 Clusa, 1993.

9 Castañer, Vicente, Comas, Boix, 1998; Castañer, Gutiérrez, Vicente, 2009.

10 Alberich, 2008.

11 Ganau, 1998; Ganau, 2001.

12 Vinuesa, 2005.

13 Módenes, 2009.

14 Roquer, Blay, 2002.

15 Alberich, 2009.

16 Ajenjo, Alberich, Medina, 2006. 
censo de 2001. Así, en relación a la movilidad por estudios, el trabajo concluye que si entre la población trabajadora la movilidad era de un 37,5\%, entre los estudiantes toma un valor ligeramente superior, un 40,4\%. De hecho, es la única característica que es similar, en tanto que el promedio de tiempo de desplazamiento es seis minutos superior - 37,4 minutos-, debido, precisamente, a que el medio de transporte mayoritario es el transporte público, que tiene una incidencia aproximada del 70\%, casi 50 puntos más elevada que en la movilidad por trabajo. Las características de los estudios explican la mayoría de las diferencias entre la movilidad intermunicipal y la intramunicipal: hay que tener en cuenta que se trata, mayoritariamente, de estudiantes de bachillerato post-obligatorio o de universitarios, de manera que los residentes en municipios pequeños donde exista un instituto de secundaria, o, incluso, los residentes en municipios más grandes pero no lo suficiente como para disponer de universidad, son los que más se mueven. Otros resultados significativos se refieren, en primer lugar, en que la diferencia entre hombres y mujeres es prácticamente nula. Aunque son algo más relevantes, los autores concluyen igualmente que tampoco son muy importantes las diferencias entre españoles y extranjeros, aunque los primeros tienen mayor movilidad que los segundos. Por otra parte, el estatus socio-económico sí que es importante, y de forma más clara que con la movilidad por motivos laborales: tanto si se mide a partir de la condición socio-económica del padre, del nivel máximo de estudios de la madre, como a partir de la superficie de la vivienda, igual que el resto de variables las posiciones más bien situadas suponen una mayor movilidad.

Otro grupo importante de trabajos donde el eje principal de análisis es la movilidad por estudios son aquellos que derivan de encuestas específicas de movilidad entre determinados colectivos de estudiantes. Aunque son diversos los centros universitarios que elaboran sus propios informes sobre las pautas y comportamientos territoriales de movilidad de sus estudiantes, en nuestro país sobresalen los trabajos, que tienen como ámbito de análisis la Universitat Autònoma de Barcelona, centro universitario que, por su localización en la periferia metropolitana de la capital catalana, posee un notable interés. ${ }^{17}$ Sin embargo, el objetivo final d estos trabajos no es tanto la cuantificación de la movilidad y la generación de una matriz de orígenes y destinos (en este caso, la propia universidad), sino que se centra en el uso de los diferentes medios de transporte para acceder al centro universitario y en relacionar esta elección con la oferta y la debilidades de la red de transporte público.

Muchos de estos trabajos se basan en la metodología ya academizada empleada en la tradición anglosajona a partir del estudio de las proporciones de población ocupada residente y de los puestos de trabajo localizados para saber, respectivamente, el grado de autocontención y de autosuficiencia de un ámbito geográfico. ${ }^{18}$ Como veremos, en la segunda parte de este artículo adaptaremos esta metodología y nomenclatura a la movilidad por estudios. En la gran mayoría de casos, se parte

17 Miralles-Guasch, Domene, 2010; Miralles-Guasch, Martínez, Marquet, 2014.

18 Smart, 1974. 
de datos procedentes del censo de población y viviendas elaborado por el Instituto Nacional de Estadística, fuente sobre la que, por lo que se afirmará a continuación, se plantean serias dudas acerca de su utilidad futura.

\section{El estudio de la movilidad a partir del censo de población}

Como se ha afirmado en la introducción y se ha podido comprobar rápidamente en apartado anterior, el estudio de la movilidad habitual de la población en Catalunya a partir de los datos censales y padronales presenta un largo historial (muy superior al del conjunto del Estado español, donde la cuestión se introduce por primera vez en 2001), puesto que ya en el censo de 1970 se adjuntó una hoja sobre los desplazamientos residencia - trabajo, ${ }^{19}$ aunque no es hasta el censo de 1981 cuando la incorporación de la movilidad no se hace en una muestra de la población sino a su conjunto, con un ámbito territorial más extenso ya que todo el territorio catalán. Hay que tener en cuenta, sin embargo, que hubo dos modelos de hoja oficial utilizados por los ayuntamientos de Catalunya: por un lado, una hoja reducida que incluía sólo las características básicas y que fue utilizado en 237 municipios que comprendían un total de 159.699 habitantes; y, por otro, una hoja ampliada que, además, solicitaba algunas características socioeconómicas y la movilidad por motivos de trabajo y de estudio, y que fue utilizado en los restantes 698 municipios con un total de 5.796 .715 habitantes. Sin embargo, el inconveniente más importante de estos datos era el hecho que se incluía la movilidad de la población que no trabajaba ni estudiaba, de forma que las personas que se desplazaban, teniendo en cuenta esta estadística, son casi el doble de las que aparecen en otras. Finalmente, en el padrón de 1986 y en el siguiente censo de 1991 se consolida la información sobre la movilidad habitual por motivos de trabajo y de estudios de la población catalana, con un cuestionario único para todo el territorio catalán, teniendo continuidad en el padrón de 1996 - como sabemos, el último realizado de manera convencional-y en el censo de 2001, de forma que, con unas pequeñas irregularidades, se dispone de información de la movilidad habitual de la población catalana desde 1986 hasta 2001 con una periodicidad quinquenal..$^{20}$

\section{Los cambios introducidos en el censo de 2001}

El censo de 2001, sin embargo, introduce algunas cuestiones nuevas, derivadas del hecho que por primera vez las preguntas sobre movilidad habitual se realizan para el conjunto del Estado español, como base para el cálculo de lo que el Instituto Nacional de Estadística (INE) denominó "población vinculada», concepto que debía sustituir al anterior de "población de hecho».21 Así, junto a las ya habituales preguntas sobre la relación entre el lugar de residencia y el de trabajo y el modo de transporte utilizado en el desplazamiento, se cuestiona también sobre el tiempo de

19 Ajenjo, 2005, p. 240-244.

20 Alberich, 2007, p. 89-93.

21 Instituto Nacional de Estadística, 2001, p. 22. 
desplazamiento y el número de viajes diarios (figura 1). No obstante, lo más reseñable es el hecho que, debido a la configuración del cuestionario, formado por varias hojas sueltas, estas preguntas se realizan únicamente para las personas de 16 años y más (edad legal mínima para poder trabajar), lo que implica que, para el caso catalán, se pierde información pues las preguntas sobre movilidad en los anteriores censos y padrones se referían a la población de 3 años o más.

El propio INE argumentaba el porqué de esta decisión con las siguientes palabras, que desde el punto de vista de la investigación son difícilmente injustificables:

Incluir los desplazamientos de la población escolar obligaría a aumentar ineficientemente el número de cuestionarios individuales o, alternativamente, a meter la pregunta en la matriz del cuestionario de hogar, donde, al no haber espacio, provocaría una reestructuración completa y muy costosa (más páginas, o formato más grande...). Además, esta información debería poder obtenerse, y con mayor precisión, de registros administrativos. ${ }^{22}$

Figura 1. Preguntas sobre movilidad entre el lugar de residencia y el lugar de estudio en el censo de población de 2001

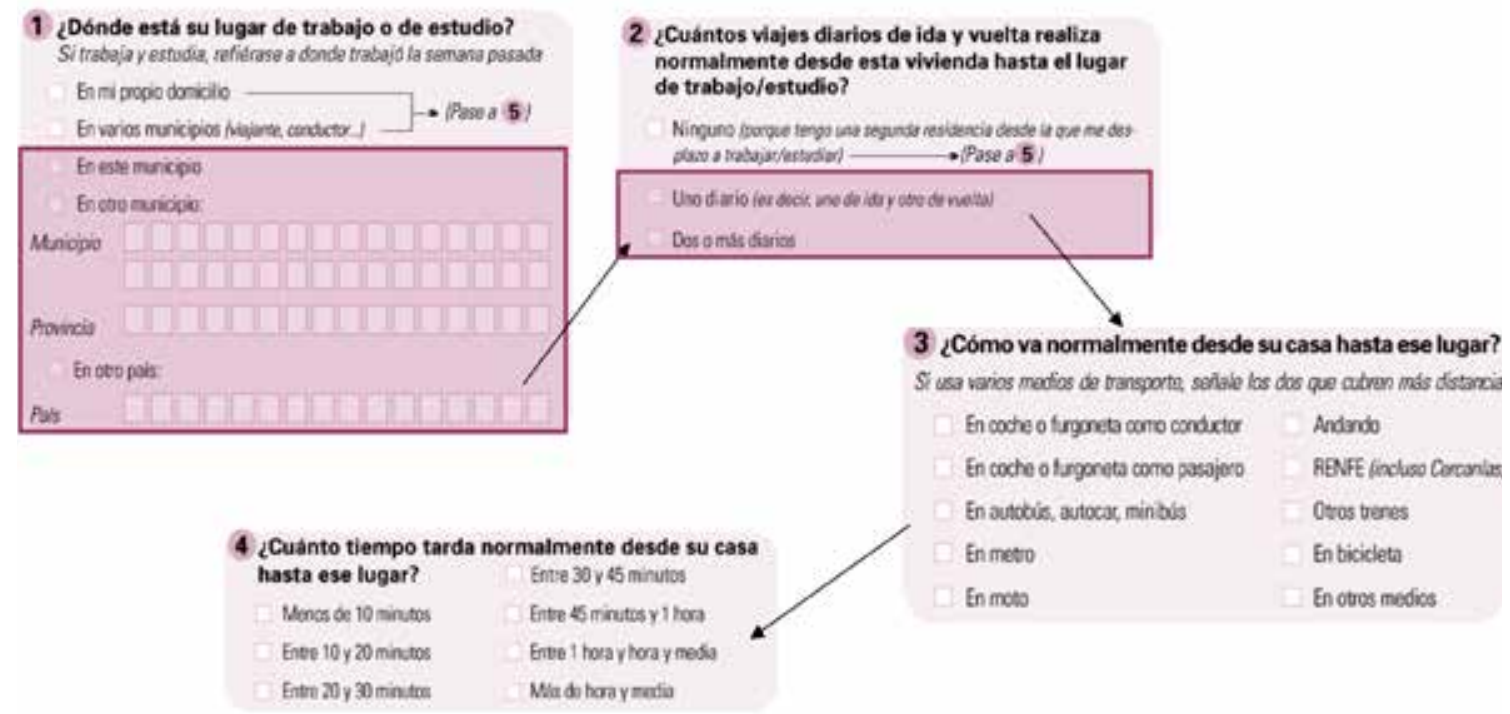

Fuente: elaboración propia a partir del Censo de población y viviendas de 2001.

Además se especificaba que "para no complicar en exceso el diseño del cuestionario individual (donde irán), las personas que trabajen y estudien a la vez deberán referirse al lugar de trabajo» (INE, 2001: 49). Es decir, que por un criterio estrictamente funcional (la disponibilidad de espacio en la hoja del cuestionario) se pierde una información valiosa y se va truncada la comparabilidad con operaciones censales anteriores.

Sin embargo, la mayor novedad del censo de $2001-y$ que en ese momento no tuvo efectos prácticos sobre la variable que nos interesa, pero sí en la concepción del censo de 2011 - es que el INE se planteó la realización de un censo clásico (con un trabajo de campo exhaustivo) pero que aprovechara, por primera vez en la tradición censal española, la existencia de ciertos registros administrativos, especialmente el Padrón continuo.

22 Instituto Nacional de Estadística, 2001, p. 49. 


\begin{abstract}
Si hay que elegir un rasgo metodológico que caracterice a estos censos, probablemente haya que mencionar el aprovechamiento, como en ningún Censo anterior, de los registros administrativos, en concreto de los Padrones Municipales de Habitantes y de la base de datos del Catastro Urbano. De hecho, la combinación de ambos directorios va a permitir efectuar un único recorrido censal (con el enorme ahorro económico que ello supone), ya que el carácter preparatorio que tradicionalmente asumía el recorrido del año terminado en 0 (que se denominaba Censos de Edificios y Locales) se va a sustituir, muy ventajosamente, por el cruce informático de ambas bases de datos. ${ }^{23}$
\end{abstract}

En efecto, el censo de 2001 sirvió para validar los datos del padrón, que desde el año 1996 había pasado a ser gestionado como un registro continuo, a través de una hoja del cuestionario, llamada precisamente de «datos padronales» que ya figura preimpresa y en la que los ciudadanos habían de indicar si los datos disponibles (nombre y apellidos, lugar y fecha de nacimiento, número de DNI, sexo, nivel de estudios y nacionalidad) eran correctos y, en caso contrario, rectificarlos. El resultado, en palabras del propio INE, fue altamente satisfactorio, con una elevada consistencia global de las características estudiadas en la operación censal. ${ }^{24}$

\title{
El cambio metodológico del censo de 2011. Implicaciones en el estudio de la mo- vilidad habitual
}

El gran problema para el estudio de la movilidad habitual a partir de los censos de población - que, como hemos visto, y a pesar de los problemas citados, se había iniciado en 2001 para el conjunto de España- se origina en el censo de 201 1, cuando el INE, aprovechando la experiencia adquirida en la operación de 2001, planteó la realización de un censo mixto, basado en la combinación de registros administrativos y una encuesta por muestreo, a semejanza de otros países como Alemania, Holanda, Polonia, Suiza o Israel (figura 2):

\begin{abstract}
Se llevará a cabo una recopilación de información procedente de diversas fuentes estadísticas y administrativas que permitan desarrollar esta estrategia formando un directorio territorial inicial y acumulando datos relativos a personas que se usarán en la forma que se describe más adelante. Está prevista la realización de un recorrido del territorio para completar y contrastar la información territorial disponible, enumerando las viviendas y recogiendo las variables de edificios. Al final de este recorrido se dispondrá de un directorio completo de la operación. Los datos sobre población que no se obtengan del tratamiento de ficheros antes mencionado se obtendrán de una gran encuesta muestral dirigida a alrededor de un 12,3\% las personas, que se podrá cumplimentar por Internet, correo o por visita de un agente censal. ${ }^{25}$
\end{abstract}

Así, el Censo de Población y Viviendas 2011 se planteó como una operación basada en la combinación, por una parte, de un fichero precensal y, por otra, de un trabajo de campo que debía incluir dos grandes operaciones: un censo de edificios exhaustivo y una encuesta por muestreo, dirigida a un porcentaje relativamente elevado de la población para conocer el resto de características de las personas y las viviendas.

23 Instituto Nacional de Estadística, 2001, p. 8.

24 Instituto Nacional de Estadística, sf, p. 14.

25 Instituto Nacional de Estadística, 2011a, p. 3. 
Figura 2. Metodología utilizada en las operaciones censales de 2011-2012 en Europa

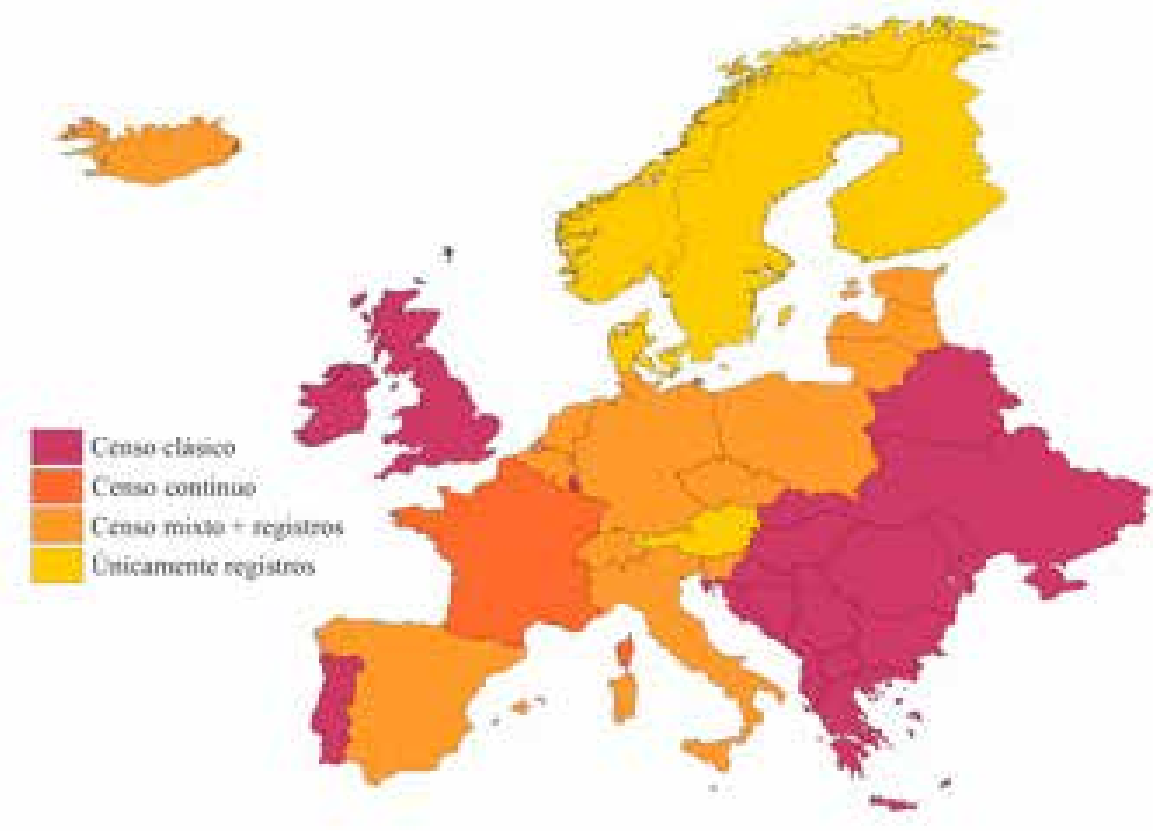

Fuente: elaboración propia a partir de datos del INE.

La idea básica era que el objetivo fundamental del fichero precensal fuera el de disponer de información suficiente para realizar el recuento de la población y el análisis de su estructura, partiendo del padrón (como se había hecho 10 años antes) pero incorporando igualmente información estadística procedente de otras fuentes administrativas (movimiento natural de la población, Seguridad Social, Agencia Tributaria, etc.), mientras que aquella que no pudiera recopilarse a partir de estas fuentes sería preguntada en la encuesta de población.

Aparte de las implicaciones de tipo económico (nos tenemos que, en realidad, las principales, sino únicas, a la hora de concebir el nuevo censo), hay que hacer, brevemente - pues no es el objetivo de este trabajo-, una serie de consideraciones epistemológicas de esta nueva metodología. En primer lugar, desde nuestro punto de vista es totalmente inaceptable que las cifras de población (volumen y estructura) resultantes sean aproximadas, con la presencia de decimales, algo totalmente contrario a la idea de stock poblacional: al partir de datos padronales, las cifras de población de determinados colectivos son matizadas por un factor de recuento que oscilan entre 0 y 1 y que estiman la probabilidad real de que una determinada persona resida o no en nuestro país en función de una serie de características demográficas (figura 3). Como el factor de recuento medio resultó ser 0,424, los 1.040.000 casos dudosos terminaron contabilizándose como una población de 440.000 personas aproximadamente. ${ }^{26}$ Ello implica, como hemos dicho, que la cifra de población publicada por el INE sea el producto de redondear la cifra resultante de esta ponderación de la población.

26 Instituto Nacional de Estadística, 2011 b, p. 6. 
Figura 3. Esquema básico de la procedencia de la información en el Censo de Población y Viviendas de 2011

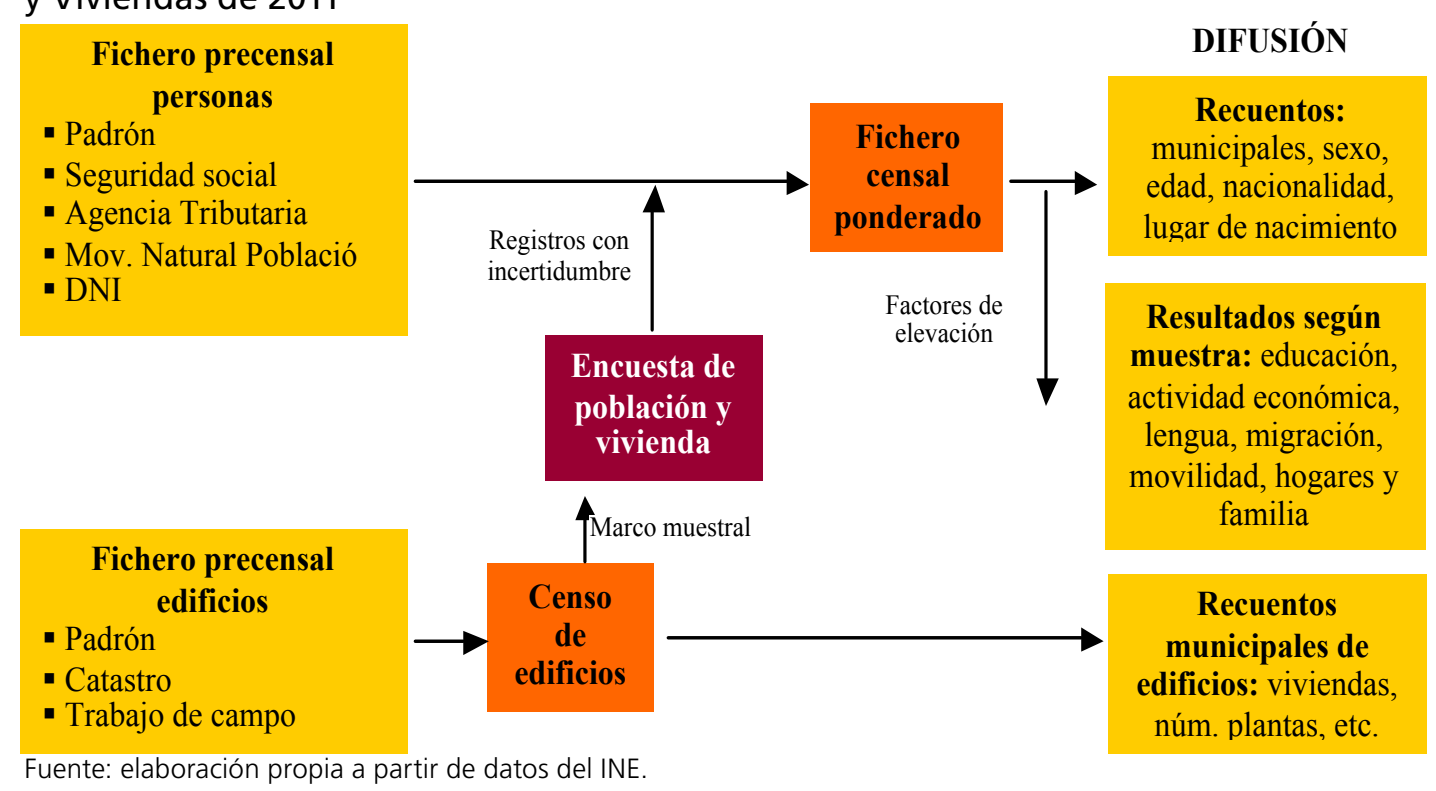

La segunda implicación, derivada de la obtención de parte de la información a partir de una muestra de población, es el hecho que se pone en entredicho el carácter universal que debe cumplir cualquier censo de población, según lo establece Naciones Unidas: ${ }^{27}$ si bien es cierto que parte de la información (aquella que figuran en el fichero precensal) se refiere a todos y cada uno de los ciudadanos españoles, hay otra (la que se obtiene a partir de la encuesta de población) que sólo está disponible para una nuestra de la población, aunque se hayan establecido todos los mecanismos de control para que ésta tenga representatividad plena para el conjunto del universo de estudio.

$\mathrm{Y}$, finalmente, en tercer lugar, y en referencia al tema que aquí nos ocupa, se pierde el detalle territorial de la información sobre la movilidad habitual (por motivos de trabajo y de estudios) de la población: es un hecho incuestionable que, debido al hecho que las preguntas sobre esta variable se realizan en la encuesta por muestreo, y por muy representativa que esta sea respecto de la población objeto de estudio, se pierde desagregación territorial, puesto que el número de entrevistas realizadas en ciertos ámbitos territoriales - pensamos explícitamente en los municipios más pequeños- es tan reducido ( $y$, en algunos casos, nulo) que los resultados, en caso de existir, son imposibles de ser extrapolables al conjunto de la población. Como algún autor ha afirmado, quizás de un modo excesivamente dramático, «se ha perdido el territorio».28

Más allá de estas cuestiones derivadas de la propia metodología del censo de 2011, tampoco el diseño del cuestionario censal contribuye a la manejabilidad y a la correcta y fácil interpretación de los datos recogidos. Tal como se muestra en la figura 4, existe un primer filtro en la información según la edad de la población: si

27 Instituto Nacional de Estadística, 1958, p. 3.

28 Feria, 2014. 
la persona tiene menos de 16 años, se le pregunta sobre si acude regularmente a un centro escolar (incluyendo las guarderías) y, en caso que la respuesta sea negativa, no se realiza ninguna otra pregunta sobre escolarización. En caso contrario, se le pregunta sobre la localización concreta de su lugar de estudio y las características de su desplazamiento (medio de transporte, tiempo de viaje...). Por su parte, la información referente a la población de 16 años y más es aún más compleja: en primer lugar, se discriminan aquellas personas que no recibieron ninguna tipo de enseñanza de las que sí, para preguntar a éstas últimas, consiguientemente, qué tipo de enseñanza (con opción de marcar hasta tres categorías distintas). Finalmente, como se hacía a las personas menores de 16 años, se pregunta sobre el lugar de estudio, aunque esta última información sólo está disponible para aquellos individuos que no trabajan, puesto que en caso de realizar ambas actividades, las respuestas a esta última pregunta se refieren al lugar de trabajo.

Figura 4. Preguntas sobre movilidad entre el lugar de residencia y el lugar de estudio en el censo de población de 2011

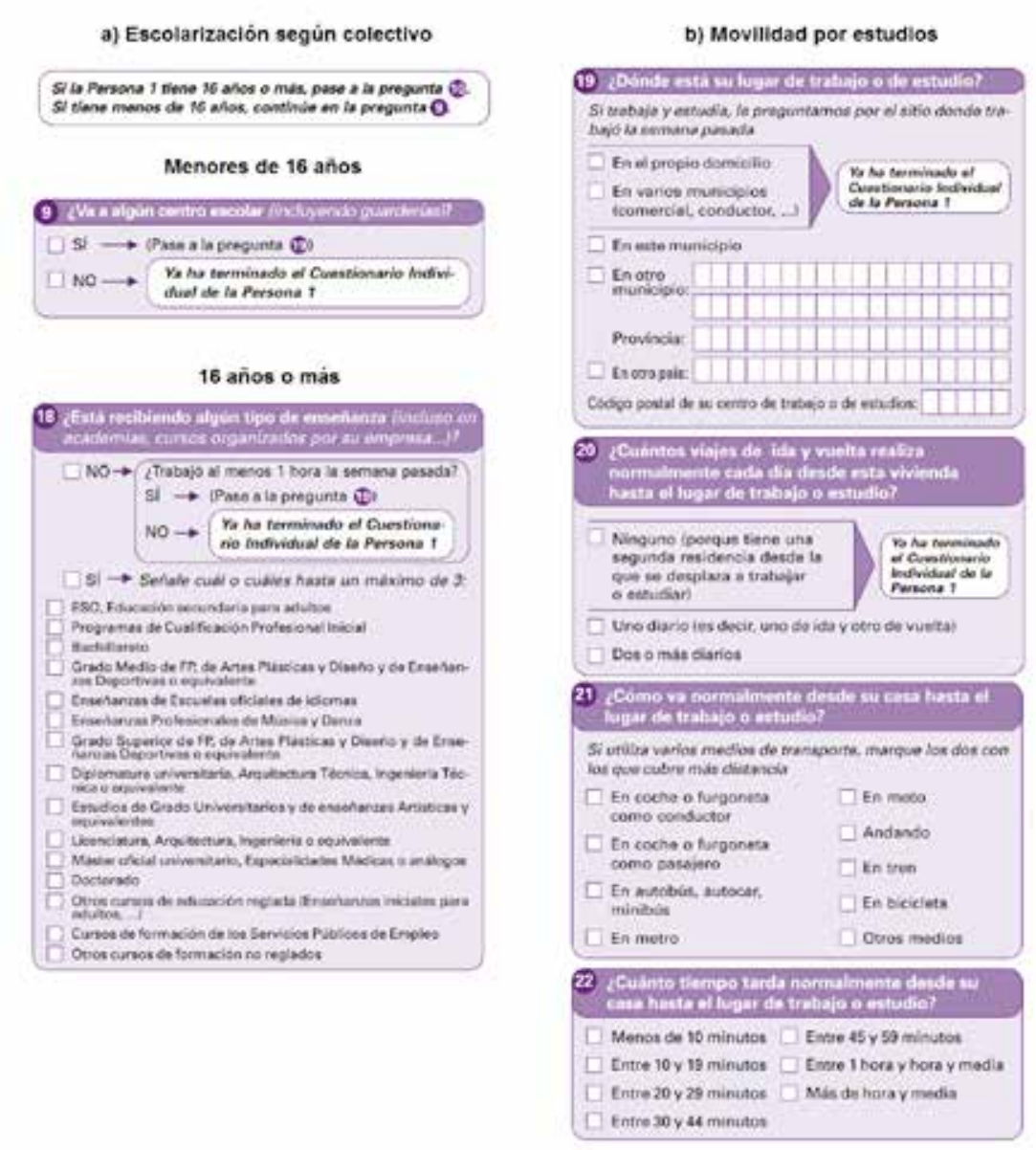

Fuente: elaboración propia a partir del Censo de población y viviendas de 2011.

Sin embargo, aparte de la propia dificultad de trabajar con la información sobre los estudios en curso según el censo de 2011 (especialmente si se quiere trabajar con los datos publicados en la web y no con el fichero de microdatos facilitado por el propio INE, el principal inconveniente de esta fuente es la pérdida de la posibilidad 
de elaborar matrices de orígenes y destinos de la movilidad a escala municipal, en tanto que el número de encuestas realizadas en cada municipio, de haberse llevado a cabo, no es significativo desde el punto de vista estadístico. Así, por un lado, las destinos (el lugar de estudio) tan sólo están disponibles para ciertos municipios (los de mayor población) puesto que en la mayoría de los casos, por causa del secreto estadístico, el detalle municipal queda obviado, agrupado en categorías de mayor ámbito territorial, como "misma provincia», etc. En segundo lugar, para aquellos pocos casos en los que sí existe el detalle municipal, los datos disponibles reflejan claramente la procedencia muestral de los datos, con todas las cifras terminadas en 0 o 5 fruto del necesario redondeo, e incluso en las celdas con menos de 50 casos, con la advertencia siguiente: «Las celdas marcadas con * pueden contener errores elevados de muestreo».

$\mathrm{Si}$, por el contrario, lo que se quiere consultar son los orígenes de los estudiantes de cada municipio, la situación es aún más desoladora. La manera de acceder a estos datos es a través de la consulta de la población vinculada de cada municipio, seleccionando únicamente aquella en que el motivo de vinculación es precisamente la movilidad por estudios. Pero, por un lado, esta información tan sólo está disponible para los municipios de más de 10.000 habitantes y, por el otro, únicamente se dispone de la cifra de población total, sin que esta aparezca desglosada según el municipio de origen.

\section{El uso de los registros administrativos. La experiencia catalana}

Como el mismo INE propone en sus proyectos censales relativos a las operaciones estadísticas de 2001 y 2011 , parte de las carencias en información derivadas de la obtención de datos a partir de una muestra de población puede (y, añadimos nosotros, debe) solucionarse mediante el uso de la información disponible en los distintos registros administrativos disponibles.

En el caso de la movilidad por motivo de estudios que nos ocupa aquí debería tratarse de una cuestión relativamente sencilla de solucionar, mediante la contraposición de la información sobre el lugar de residencia y el lugar de estudio que figura en la hoja de matriculación. Como las competencias en materia de educación están transferidas a las comunidades autónomas, son cada uno de los gobiernos autonómicos los que gestionan, a través de los organismos correspondientes, la matriculación en todos los niveles educativos y, por consiguiente, los que disponen de dicha información.

En el caso analizado aquí, la Generalitat de Catalunya centraliza esta información a través de dos organismos: por un lado, para los estudios no universitarios, la Secretaria General d'Ensenyament, que depende del Departament d'Ensenyament, mientras que por el otro, la Secretaria de Universitats i Recerca, perteneciente al Departament d'Economia i Coneixement, gestiona todo lo relacionado con la educación superior.

Aprovechando esta coyuntura, el IDESCAT - en una experiencia pionera, pues 
no nos consta que ningún otro organismo autonómico haya realizado una explotación similar - viene realizando desde el año 2011 (los datos se refieren al curso 2011-2012, puesto que el año de referencia es el del inicio del curso) la explotación estadística de la información proporcionada por estos dos organismos referentes a la matriculación del alumnado en Catalunya (resida o no en la comunidad autónoma) en todos los niveles formativos, desde la etapa de enseñanza infantil de segundo ciclo (a partir de los tres años) hasta la etapa de estudios superiores postobligatorios. En consecuencia, esta estadística excluye el alumnado de educación infantil de primer ciclo (0-2 años), las enseñanzas de régimen especial (música, danza, deportes, idiomas, artes plásticas y diseño, estudios superiores de diseño, arte dramático, conservación y restauración de bienes culturales) y las enseñanzas de personas adultas. En relación a los estudios universitarios, los datos recogen la matriculación en las doce universidades catalanes, ya sean públicas o privadas (todas excepto la Universitat Oberta de Catalunya, que no es presencial), de los centros integrados y adscritos y de los niveles educativos de ciclos, grados y masters con titulaciones homologadas, por lo que se excluyen los niveles educativos de doctorado y les titulaciones propias (no homologadas).

Por lo que se refiere a los programas de movilidad con el extranjero, no se incluyen los alumnos matriculados en otras universidades que cursan sus estudios en una universidad catalana, ni tampoco los alumnos matriculados en una universidad catalana que están realizando una estancia en una universidad extranjera.

En referencia a la información publicada, y en relación a la población en edad escolar, los datos se difunden según el lugar de residencia, el lugar de estudio, el sexo, el grupo de edad (agrupado en las categorías «3-5 años», "6-11 años», «12-15 años», «16-17 años» y «18 años y más») y el nivel de estudios («Educación infantil de segundo ciclo», «Educación primaria», «Educación secundaria obligatoria», «Bachillerato", "Ciclos formativos de grado medio" y "Ciclos formativos de grado superior»), mientras que para los estudios universitarios solo están disponibles los datos sobre el lugar de residencia, el lugar de estudio y el sexo.

En concreto, para el estudio de la movilidad se usa dos variables claves: por un lado, el municipio de residencia del alumnado y, por el otro, el municipio donde se sitúa el centro educativo en el que está matriculado. La información referente al cruce de estas dos variables se hace desde ambos puntos de vista: las tablas centradas en el lugar de residencia permiten calcular los alumnos residentes (en adelante, $\mathrm{AR}$, a semejanza de la población ocupada residente que se calculaba a partir de los datos del censo) y la variable del lugar de estudio se halla categorizada en cuatro grupos: «en el mismo municipio», "en el resto de la comarca», "en el resto del ámbito del Pla territorial (las futuras veguerías» y "en el resto de Catalunya» (como puede observarse, los datos no permiten conocer el número de alumnos residentes en Catalunya que estudian fuera del ámbito de la comunidad autónoma). Por el contrario, las tablas centradas en el lugar de estudio permiten calcular el número de plazas de estudio localizadas (PEL) en cada ámbito y desglosan la información sobre el 
lugar de residencia en varios categorías: «en el mismo municipio», «en el resto de la comarca», «en el resto del ámbito territorial», "en el resto de Catalunya», "fuera de Catalunya» $y$ «No consta».

Como puede deducirse de esta desagregación territorial, tal y como está publicada en la web, la información no permite tampoco recrear la matriz origen-destino de la movilidad a escala municipal, pero sí permite calcular, para todos los municipios catalanes (y no sólo los mayores de 10.000 habitantes), indicadores básicos de movilidad como los de autocontención y autosuficiencia, y otros de tipo complementario, como el índice de especialización funcional (la relación entre los AR y los PEL de cada municipio).

Por el contrario, la información presenta, entre otros aspectos, dos puntos fuertes. En primer lugar, la estadística recoge la movilidad de la población que cursa una enseñanza oficial, con independencia de cuál sea su situación laboral (ocupado, desocupado u otras situaciones), hecho que no pasaba en los censos de población 2001 y 2011 , cundo la información se refería únicamente a las personas desocupadas que cursaban algún tipo de estudio (ya que para la población ocupada las preguntas sobre su movilidad se referían exclusivamente a la derivada de la localización de su puesto de trabajo en relación a la de su residencia). En segundo lugar, y no menos importante, el otro punto a destacar de la estadística es su periodicidad anual, en contra de la información cada diez años que proporcionaban los censos: así, en el momento de redactar estas líneas (enero de 2016), en la web de IDESCAT están disponibles los datos referentes a los cursos escolares 2011-2012, 2012-2013, 2013-2014 y 2014-2015 (aunque este último año únicamente para la población en edad escolar, sin información, aún, de la movilidad de los estudiantes universitarios).

\section{La movilidad por motivos de estudio en Catalunya, 2011-2015}

Los datos publicados en la web del IDESCAT permiten, pues, analizar, con datos anuales, por un lado, cuál ha sido la evolución de las dos principales magnitudes de la educación en Catalunya - los alumnos residentes (AR) y los puestos de trabajo localizados (PEL) - y, por el otro, lo que más nos interesa aquí, la movilidad que se deriva de la diferente localización en el espacio de estas dos variables. Así, en primer lugar, se hará un breve análisis para el conjunto de Catalunya de la evolución de ambas magnitudes, y, en segundo lugar, y a partir de indicadores clásicos (autocontención, autosuficiencia y especialización funcional) el estudio de la movilidad a escala municipal.

\section{La evolución de los alumnos residentes y los puestos de estudio localizados}

La evolución de los AR y los PEL en Catalunya para el periodo 2011-2015 se muestran en el caudro 1. Por lo que se refiere a los AR los datos muestran un ligero aumento en los últimos años, hasta situarse en las 1.349 .462 personas en el curso académico 2013-2014 (último para el que disponemos de información para todos los niveles educativos), fruto sobretodo del incremento de los alumnos en la educación 
no universitaria, especialmente significativo en educación primaria, a causa de la estructura por edades favorables fruto del repunte de la natalidad, y entre el alumnado de la formación profesional. Por el contrario, el número de alumnos que cursan estudios universitarios mantiene una tendencia hacia la estabilización, cuando no a la disminución. Nuevamente, la estructura demográfica parece influir en este hecho, con la llegada a la mayoría de edad de las cohortes poco numerosas nacidas a principios de la década de los años noventa, aunque en este caso debe añadirse necesariamente el efecto de la crisis económica que, en el caso catalán, ha venido acompañada de un aumento significativo del precio de las tasas universitarias sin que esta política haya venido respaldada por un aumento paralelo en la dotación y la cuantía de becas y ayudas económicas.

Cuadro 1. Evolución del número de alumnos residentes y puestos de estudio localizados según el tipo de estudios en Catalunya. Cursos 2011-2012 a 2014-2015

\begin{tabular}{|c|c|c|c|c|c|c|c|}
\hline \multirow{2}{*}{$\begin{array}{l}\text { Curso } \\
\text { académico }\end{array}$} & \multicolumn{3}{|c|}{ Alumnos residentes (AR) } & \multicolumn{3}{|c|}{$\begin{array}{l}\text { Puestos de estudio localizados } \\
\text { (PEL) }\end{array}$} & \multirow{2}{*}{$\begin{array}{r}\text { Diferencia } \\
\text { PEL-AR }\end{array}$} \\
\hline & No univ. & Univ. & Total & No univ. & Univ. & Total & \\
\hline 2014-2015 & 1.195 .397 & n. d. & n. d. & 1.205 .033 & n. d. & n. d. & n. d. \\
\hline 2013-2014 & 1.192 .024 & 157.438 & 1.349 .462 & 1.200 .535 & 189.763 & 1.390 .298 & 40.836 \\
\hline $2012-2013$ & 1.175 .220 & 155.628 & 1.330 .848 & 1.178 .138 & 191.502 & 1.369 .640 & 38.792 \\
\hline $2011-2012$ & 1.180 .484 & 157.735 & 1.338 .219 & 1.184 .395 & 193.076 & 1.377 .471 & 39.252 \\
\hline
\end{tabular}

Fuente: elaboración propia a partir de datos del IDESCAT.

La evolución de PEL es similar a la observada para los AR, ya que en su inmensa mayoría la población estudiante residente en Catalunya cursa sus estudios en esta misma comunidad autónoma, y, por el contrario, el volumen de la población no residente que se desplaza a Catalunya se sitúa de forma estable alrededor de las 40.000 personas, con especial protagonismo de los estudiantes universitarios.

\section{La evolución de los indicadores de movilidad. Una perspectiva general}

Introduciendo la variable relativa a la movilidad, se han calculado dos índices clásicos: en primer lugar, desde el punto de vista de los AR, el llamado indicador de autocontención, que mide el porcentaje de estudiantes que cursan sus estudios en su mismo ámbito de residencia; y, en segundo lugar, el indicador de autosuficiencia, es decir, el porcentaje de PEL de un territorio ocupados por residentes en él. El análisis se ha completado con un tercer indicador, no específicamente de movilidad, llamado de especialización funcional, que pone en relación el número de AR y PEL de cada municipio. Si tomamos como referencia la escala municipal, la formulación 
de dichos indicadores es, pues, la siguiente:

$$
\begin{gathered}
\text { Autocontención }=\frac{\text { AR que estudia en el propio municipio }}{\text { AR total }} \times 100 \\
\text { Autosuficiencia }=\frac{\text { PEL ocupados por AR del propio municipio }}{\text { PEL total }} \times 100 \\
\text { Especialización }=\frac{\text { AR del municipio }}{\text { PEL del municipio }}
\end{gathered}
$$

Los datos del cuadro 2 nos muestran unos valores de ambos indicadores de movilidad bastante elevados, por encima del 75\%, aunque, sin embargo, este hecho esconde un comportamiento claramente diferencial según el tipo de estudio cursado. Así, centrándonos en la autocontención, tan sólo el 15\% de los alumnos no universitarios realiza un desplazamiento intermunicipal (los valores son muy similares en los cuatro cursos académicos para los cuales se dispone de datos). Este hecho es lógico teniendo en cuenta que la movilidad es especialmente reducida en las etapas formativas iniciales, pues la oferta de plazas en educación infantil y primaria tiende a ser muy amplia y generalizada en la mayoría de los municipios, algo que no pasa en los niveles formativos siguientes: por ejemplo, para el curso 2014-2015, la autocontención municipal en la educación infantil y primaria supera el $90 \%$ de media, mientras que en el bachillerato se reduce al 76,2\% y en la formación profesional, al $46,1 \%$. Por el contrario, y siguiendo esta misma lógica, el nivel de autocontención municipal de la población que cursa estudios universitarios es de poco más del $25 \%$, lo que no debe extrañar teniendo en cuenta la localización puntual en el territorio de este tipo de equipamientos educativos: por definición, sólo puede haber valores de autocontención en aquellos municipios que disponen de una facultad o escuela universitaria.

Por su lado, la autosuficiencia presenta un comportamiento muy similar, sobre todo en los niveles de estudios no universitarios, ya que al no existir prácticamente flujos con el resto del territorio español (de los 1.195.397 PEL en Catalunya en el curso 2014-2015, tan sólo 1.921 personas residían fuera de esta comunidad autónoma y de otras 7.715 se desconoce su lugar de residencia), el sistema educativo catalán en estas etapas formativas actúa prácticamente como un sistema cerrado, con un número muy similar de AR y PEL. No pasa lo mismo en los niveles universitarios, puesto que aquí la autosuficiencia es sensible menor que la autocontención, con valores todos los cursos académicos analizados alrededor del $22 \%$. En este caso, a la ya citada localización puntual en el territorio de los centros formativos hay que añadirle una mayor apertura del sistema universitario catalán, ya que de los 189.763 PEL existentes en el curso 2013-2014, 21.130 eran ocupados por residentes fuera de Catalunya y otros 11.195 por personas cuyo lugar de residencia se desconoce. 
Cuadro 2. Autocontención, autosuficiencia y especialización funcional municipales según el tipo de estudios en Catalunya. Cursos 2011-2012 a 2014-2015

\begin{tabular}{lcccccccccc}
\hline \multirow{2}{*}{$\begin{array}{l}\text { Curso } \\
\text { académico }\end{array}$} & \multicolumn{3}{c}{ Autocontención } & \multicolumn{3}{c}{ Autosuficiencia } & \multicolumn{3}{c}{ Especialización funcional } \\
\cline { 2 - 10 } & $\begin{array}{c}\text { No } \\
\text { univ. }\end{array}$ & Univ. & Total & $\begin{array}{c}\text { No } \\
\text { univ. }\end{array}$ & Univ. & Total & $\begin{array}{c}\text { No } \\
\text { univ. }\end{array}$ & Univ. & Total \\
\hline $2014-2015$ & $84,3 \%$ & n.d. & n. d. & $83,6 \%$ & n. d. & n.d. & 0,99 & n.d. & n. d. \\
$2013-2014$ & $84,4 \%$ & $26,5 \%$ & $77,6 \%$ & $83,8 \%$ & $22,0 \%$ & $75,4 \%$ & 0,99 & 0,83 & 0,97 \\
$2012-2013$ & $84,6 \%$ & $27,1 \%$ & $77,8 \%$ & $84,3 \%$ & $22,0 \%$ & $75,6 \%$ & 1,00 & 0,81 & 0,97 \\
$2011-2012$ & $84,4 \%$ & $27,7 \%$ & $77,7 \%$ & $84,1 \%$ & $22,6 \%$ & $75,5 \%$ & 1,00 & 0,82 & 0,97 \\
\hline
\end{tabular}

Fuente: elaboración propia a partir de datos del IDESCAT.

Por lo que se refiere a la especialización funcional (la relación entre el número de AR y PEL), hay que destacar que el valor para el conjunto de los distintos niveles formativos es muy cercano a 1, lo que equivale a afirmar que el número de AR y de PEL en Catalunya es muy similar, como ya se ha comentado anteriormente. En términos de movilidad, que el valor no sea igual a 1 implica que, aunque el sistema educativo catalán actúa como un conjunto bastante cerrado en si mismo, con pocos flujos de movilidad con el resto del territorio español, sí existe una cierta atracción de alumnado residente en otros territorios. Este hecho es especialmente relevante en el caso de les estudios universitarios, pues en este nivel formativo se concentran más del $80 \%$ del «excedente» de PEL en Catalunya, de modo que hasta 32.325 plazas de las universidades catalanas son ocupadas por residentes en otras comunidades autónomas o en el extranjero, lo que explica un valor del indicador de especialización funcional alrededor de 0,82. Por el contrario, la equiparación entre el número de PEL y AR en los niveles no universitarios es prácticamente total, lo que determina un valor del indicador muy próximo a 1 en todos los cursos académicos analizados.

Cuadro 3. Autocontención y autosuficiencia municipales según el sexo y la edad de la población no universitaria en Catalunya. Curso 2014-2015

\begin{tabular}{llcc}
\hline Variable & Categoría & Autocontención & Autosuficiencia \\
\hline \multirow{2}{*}{ Sexo } & Hombre & $84,0 \%$ & $83,3 \%$ \\
& Mujer & $84,6 \%$ & $83,9 \%$ \\
\hline \multirow{2}{*}{ Edad } & De 3 a 5 años & $92,4 \%$ & $91,9 \%$ \\
& De 6 a 11 años & $91,1 \%$ & $90,4 \%$ \\
& De 12 a 15 años & $83,8 \%$ & $83,2 \%$ \\
& De 16 a 17 años & $72,9 \%$ & $72,5 \%$ \\
\hline \multirow{2}{*}{ Total } & De 18 años y más & $49,4 \%$ & $48,6 \%$ \\
\hline
\end{tabular}

Fuente: elaboración propia a partir de datos del IDESCAT. 
Finalmente, la introducción de las variables demográficas básicas, el sexo y la edad, únicamente disponibles para la población que cursa estudios no universitarios, nos muestra algún dato interesante (cuadro 3): mientras que entre sexos no hay diferencias significativas, sí se observa una graduación clara en relación a la edad, en el sentido que a una mayor edad le corresponde una mayor apertura. Sin duda alguna, la edad representa una clara interrelación con el nivel formativo cursado, de modo que la interpretación anteriormente expuesta es válida para igualmente para la variable edad.

\section{La evolución de los indicadores de movilidad. Una perspectiva municipal}

Obviamente los valores de ambos indicadores de autocontención y autosuficiencia aumentan a medida que se amplía el ámbito de estudio: así, si tomamos como referencia la escala comarcal, para el curso 2013-2014 la autocontención se eleva al $89,0 \%$ (95,1\% entre los no universitarios y $42,7 \%$ entre los universitarios) y la autosuficiencia al 86,4\% (94,2\% y 35,4\%, respectivamente). Y si la escala de análisis es el conjunto de Catalunya, la autocontención se eleva al 100\% (ya hemos comentado que no se dispone de los datos de los AR que cursan sus estudios fuera de la comunidad autónoma), mientras que la autosuficiencia asciende hasta el 97,1\% (prácticamente el $100 \%$ en los estudios no universitarios y del 83,0\% en el de los estudios universitarios, de modo que un $17,0 \%$ del alumnado de este nivel formativo procede de Catalunya o no conocemos su lugar de residencia).

Volviendo a la escala de análisis municipal, resulta interesante comprobar si existe un patrón en la distribución territorial de los niveles de los indicadores analizados. Si nos centramos en el primero de los indicadores, el de la autocontención (figura 4), lo que debe indicarse en primer lugar es que de los 947 municipios catalanes, hay 218 (representados de color gris en los mapas) donde el valor del indicador es 0 para los alumnos de niveles no universitarios, puesto que no hay PEL en su término municipal y, en consecuencia, necesariamente los AR deben realizar una movilidad intermunicipal. La cifra aumenta hasta los 935 municipios entre el alumnado universitarios (la oferta universitaria catalana se concentra únicamente en 22 municipios), de los cuales 894 presentan valores de AR, mientras que en los otros 31 simplemente no residía nadie que estuviera cursando este tipo de estudios durante el curso 2013-2014.

Entre los estudios no universitarios, el municipio que presenta una mayor autocontención es, evidentemente, la ciudad de Barcelona (97,6\%), seguido de otras poblaciones importantes como Lleida, Mataró, Amposta o la Seu d'Urgell, es decir, capitales comarcales situadas a una cierta distancia de la capital catalana. De hecho, todas las capitales de 41 comarcas $^{29}$ presentan valores de autocontención superiores al $85 \%$ - excepto la que es más próxima a Barcelona, Sant Feliu de Llobregat, cuyo indicador se sitúa en el $82,5 \%$ - y son, sistemáticamente, los municipios que pre-

29 Desde el año 2015 existe una nueva comarca, el Moianès, con capital en el municipio de Moià, creada oficialmente el 23 de abril de 2015. 
sentan una autocontención mayor en cada comarca. En este sentido, la proximidad a Barcelona o a una capital comarcal es un factor que determina un menor valor de autocontención: por la mayor oferta de PEL que estas ofrecen, ejercen un papel de atracción sobre el alumnado residente en sus entornos municipales más próximos, especialmente entre los niveles formativos superiores (bachillerato y formación profesional), por su menor oferta existente en el territorio.

Figura 4. Autocontención municipal según el tipo de estudios en Catalunya. Curso 2013-2014

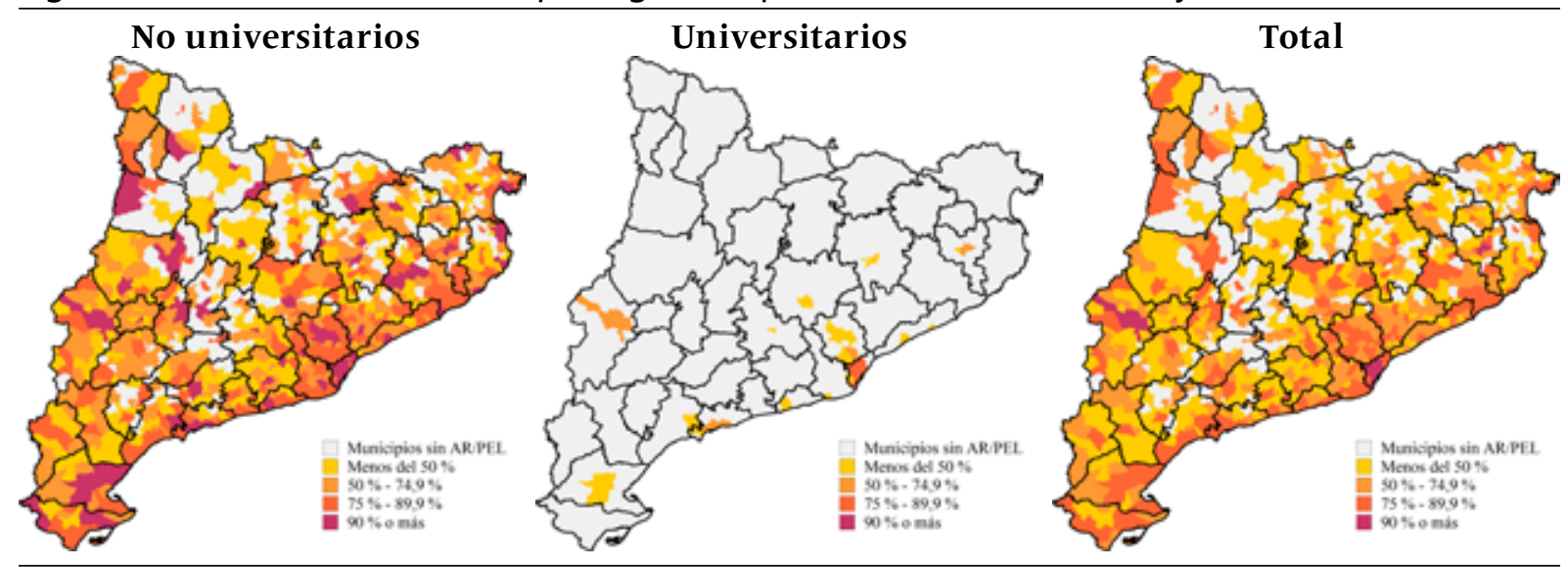

Fuente: elaboración propia a partir de datos del IDESCAT.

Por su lado, la autocontención municipal de los matriculados en estudios universitarios se ve muy condicionada, como se ha comentado, por la propia localización de la oferta, que sólo abarca un total de 22 municipios. De éstos, Barcelona es nuevamente el municipio con mayor autocontención (75\%), sin duda alguna por su amplia y variada oferta formativa, seguida del resto de capitales provinciales - Lleida $(69,1 \%)$, Girona $(61,7 \%)$ y Tarragona $(53,5 \%)$ - y el caso especial de Cerdanyola del Vallès $(59,6 \%)$, que acoge en su término municipal el campus de la Universitat Autònoma de Barcelona.

Por lo que se refiere a la autosuficiencia (figura 5), debe indicarse que hay 216 municipios sin PEL y, por tanto, para los cuales carece de sentido calcular el indicador y otros dos casos donde éste toma valor 0, a pesar de contar con PEL: es el caso de Talarn, donde sus 31 PEL son ocupados por estudiantes residentes en otro municipio ya que sus 44 AR se desplazan igualmente a otro municipio, y de la Canonja, cuyos 1.193 PEL son ocupados por foráneos, mientras que sus 106 AR estudian fuera del municipio. Probablemente en ambos casos se trate de un error en los datos originados, quizás propiciado en el caso de la Canonja por su reciente segregación respecto del municipio de Tarragona, que quizás ha conllevado una tabulación errónea en los datos de movilidad de su población residente.

Centrándonos en los casos que sí ofrecen un resultado válido del indicador, debe indicarse que en esta ocasión no son las capitales comarcales las que presentan un mayor nivel de autosuficiencia, sino, en términos generales pequeños municipios de entornos rurales del interior de Catalunya principalmente. Se trata, sin duda alguna, de pueblos pequeños, que cuentan únicamente con una escuela de educa- 
ción infantil y primaria y/o un instituto de educación secundaria cuyos alumnos proceden mayoritariamente del propio municipio. Es el caso, por ejemplo, de los 69 municipios donde el indicador alcanza el valor máximo del $100 \%$.

En una situación opuesta se encuentran las principales ciudades del país: aun con un valor elevado (86,3\%), la ciudad de Barcelona ocupa el puesto 382 del ranking de mayor autosuficiencia a escala municipal, a semejanza de lo que pasa en otras capitales. Este hecho confirma el papel de atracción que estos municipios ejercen sobre los territorios más próximos, de manera que su oferta formativa -en volumen y variedad - supera la lógica municipal para responder a una necesidad comarcal. Por su parte, poco puede decirse de los 22 municipios con PEL de formación universitaria, salvo el hecho que ninguno de ellos llega al 35\% de autosuficiencia, lo que confirma el papel atractivo de este tipo de centros educativos.

Figura 5. Autosuficiencia municipal según el tipo de estudios en Catalunya. Curso 2013-2014

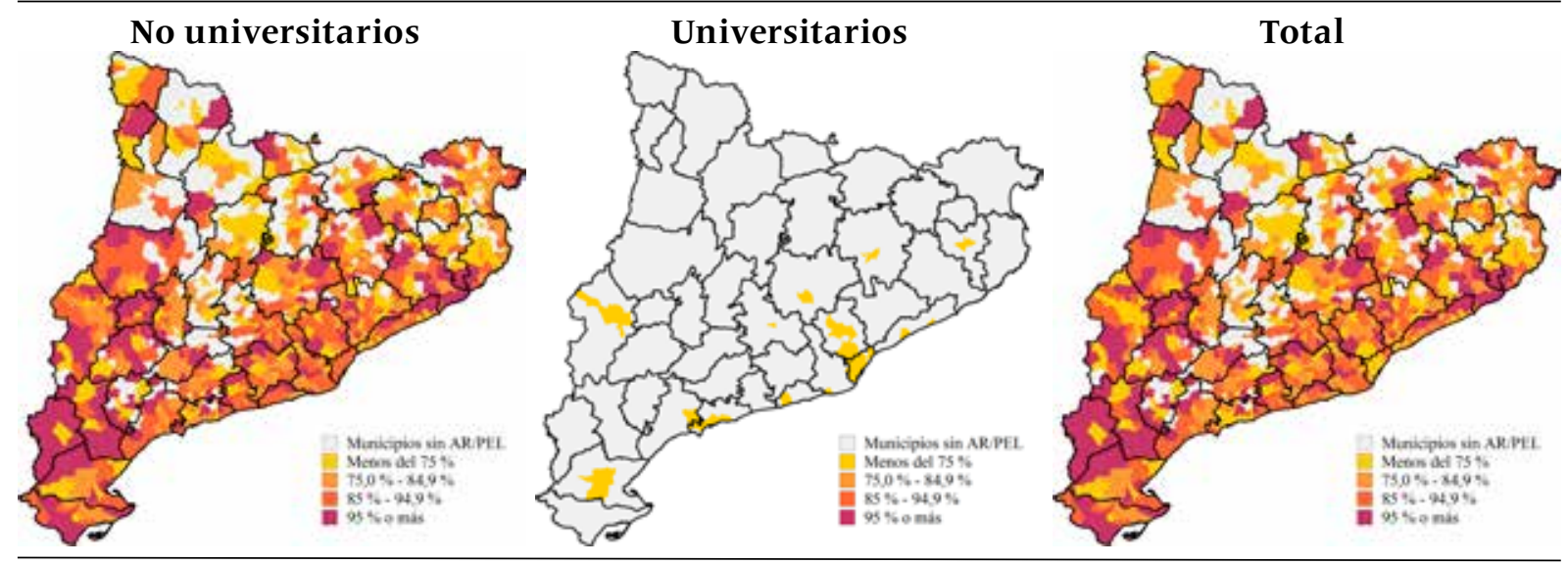

Fuente: elaboración propia a partir de datos del IDESCAT.

Finalmente, en relación a la especialización funcional (figura 6), cabe señalar que únicamente 104 municipios (de los 947 existentes en Catalunya) presentan un mayor número de PEL que de AR (con un valor del indicador, pues, por debajo de 1 ), mientras que 625 igualan o superan este valor y en los 218 restantes no ha sido posible calcular el indicador por no disponer de PEL en su término municipal. La mayor parte de los municipios con PEL $>$ AR corresponden, principalmente, a ciertas capitales comarcales y otros municipios importantes, además de algunos otros casos de municipios pequeños donde los datos pueden reflejar cierta aleatoriedad y, por tanto, sin una significación estadística relevante. Por ejemplo, la ciudad de Barcelona presenta un valor del indicador de 0,75 (el vigésimo cuarto valor más bajo), similar a otras capitales comarcales como Girona $(0,59)$, Vic $(0,65)$, Lleida $(0,71)$ o Tarragona $(0,79)$. Este hecho, unido a los valores obtenidos por municipios próximos, permite corroborar la hipótesis que acabamos de apuntar sobre el rol comarcal (e incluso regional en el caso de Barcelona) de la oferta, en cuanto a volumen y variedad, de ciertos municipios, que atraen AR de los territorios más cercanos.

Esta afirmación es válida tanto para el conjunto de los niveles formativos como para cada uno de sus subconjuntos (estudios no universitarios y estudios universi- 
tarios), pues entre los municipios con presencia de estudios de tercer ciclo, únicamente en siete casos (Mataró, l'Hospitalet de Llobregat, Esplugues de Llobregat, Sabadell, Igualada, Tortosa y Badalona) la demanda (AR) es superior a la oferta (PEL). En el extremo contrario, se sitúan municipios con un gran volumen de oferta, como Cerdanyola del Vallès (Universitat Autònoma de Barcelona), Vic (Universitat de Vic), Girona y Salt (Universitat de Girona), Lleida (Universitat de Lleida), Tarragona (Universitat Rovira i Virgili), Barcelona (Universitat de Barcelona y Universitat Pompeu Fabra, entre otras).

Figura 6. Autosuficiencia municipal según el tipo de estudios en Catalunya. Curso 2013-2014

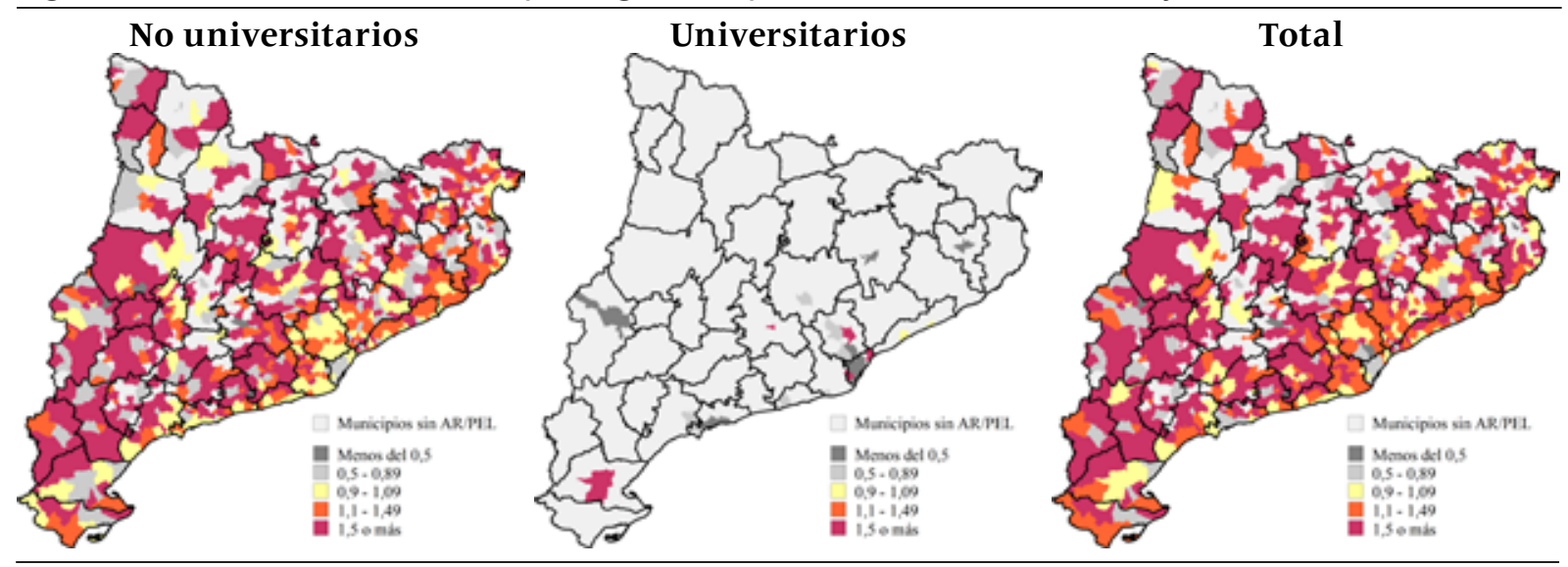

Fuente: elaboración propia a partir de datos del IDESCAT.

Más allá de la distribución territorial de la movilidad mostrada en los mapas de las figuras previas, otra posible perspectiva a la hora de analizar los patrones espaciales de la movilidad a escala municipal pasa por realizar un estudio de qué sucede en función del tamaño del municipio de residencia: ¿presentan una mayor movilidad los municipios más pequeños o, por el contrario, son los más poblados los que muestran una mayor capacidad de atracción de población estudiante no residente? Por este motivo, en base a los datos del curso 2013-2014, se han calculado de nuevo los indicadores de movilidad (autocontención, autosuficiencia y especialización funcional) agrupando los municipios en función de su tamaño poblacional en base a la población registrada en el padrón de población a fecha 1 de enero 2013.

Los datos mostrados en el cuadro 4 son muy concluyentes en relación al indicador de autocontención: en ambos niveles formativos (no universitarios y universitarios), se aprecia una clara gradación en función del tamaño municipal, en el sentido que el indicador aumenta su valor a medida que también lo hace el tamaño municipal, correspondiendo, pues, el valor mínimo a los municipios de menos de 500 habitantes ( 19,8\%) y el máximo a la ciudad de Barcelona (93,6\%). Algo parecido sucede en el caso del indicador de autosuficiencia, aunque la gradación no es tan clara y actúa en sentido inverso: el valor menor se produce en este caso en los municipios de 500 a 2.000 habitantes $(79,8 \%)$, correspondiendo nuevamente el valor mínimo a la ciudad de Barcelona $(70,1 \%)$. Estos valores se ven muy condicionados por los obtenidos entre los estudiantes no universitarios (que, como hemos visto, 
son mayoritarios en términos absolutos), aunque la gradación es aún más acentuada entre los universitarios.

Finalmente, en relación al índice de especialización funcional también permite extraer conclusiones claras, en el sentido que son los municipios de mayor tamaño donde la relación entre la oferta (PEL) y la demanda (AR) locales es más favorable a la primera: por debajo de los 25.000 habitantes, los municipios poseen un mayor número de AR que PEL, mientras a partir de este umbral la tendencia se invierte. En este sentido, cabe indicar que el valor especialmente elevado entre los estudios universitarios de los municipios de 5.000 a 25.000 habitantes se debe a la prácticamente nula oferta de este tipo de estudios en municipios de este tamaño poblacional: tan sólo Vila-seca (con un campus de la Universitat Rovira i Virgili) y Sant Pol de Mar (donde existe un centro adscrito a la Universitat de Girona) corresponden a esta categoría.

Cuadro 4. Autocontención, autosuficiencia y especialización funcional municipales según el tamaño municipal y el tipo de estudios en Catalunya. Curso 2013-2014

\begin{tabular}{lccccccccc}
\hline \multirow{2}{*}{$\begin{array}{l}\text { Tamaño } \\
\text { municipal } \\
\text { (habitantes) }\end{array}$} & \multicolumn{3}{c}{ Autocontención } & \multicolumn{3}{c}{ Autosuficiencia } & \multicolumn{3}{c}{ Especialización funcional } \\
\cline { 2 - 9 } & $\begin{array}{c}\text { No } \\
\text { univ. }\end{array}$ & Univ. & Total & $\begin{array}{c}\text { No } \\
\text { univ. }\end{array}$ & Univ. & Total & $\begin{array}{c}\text { No } \\
\text { univ. }\end{array}$ & Univ. & Total \\
\hline$<\mathbf{5 0 0}$ & $22,3 \%$ & - & $19,8 \%$ & $79,8 \%$ & - & $79,8 \%$ & 3,58 & - & 4,03 \\
$\mathbf{5 0 0 - 1 . 9 9 9}$ & $48,6 \%$ & - & $43,4 \%$ & $76,0 \%$ & - & $76,0 \%$ & 1,56 & - & 1,75 \\
$\mathbf{2 . 0 0 0 - 4 . 9 9 9}$ & $60,6 \%$ & - & $54,5 \%$ & $76,8 \%$ & - & $76,8 \%$ & 1,27 & - & 1,41 \\
$\mathbf{5 . 0 0 0 - 2 4 . 9 9 9}$ & $81,1 \%$ & $0,1 \%$ & $72,9 \%$ & $81,7 \%$ & $5,6 \%$ & $81,5 \%$ & 1,01 & 56,18 & 1,12 \\
$\mathbf{2 5 . 0 0 0 - 9 9 . 9 9 9}$ & $85,9 \%$ & $10,1 \%$ & $77,8 \%$ & $82,9 \%$ & $6,7 \%$ & $71,6 \%$ & 0,96 & 0,66 & 0,92 \\
$\mathbf{1 0 0 . 0 0 0 ~ o ~ m a ́ s ~}$ & $91,1 \%$ & $20,5 \%$ & $83,6 \%$ & $87,7 \%$ & $18,3 \%$ & $79,7 \%$ & 0,96 & 0,89 & 0,95 \\
Barcelona & $97,5 \%$ & $75,0 \%$ & $93,6 \%$ & $86,3 \%$ & $32,3 \%$ & $70,1 \%$ & 0,88 & 0,43 & 0,75 \\
\hline Catalunya & $84,4 \%$ & $26,5 \%$ & $77,6 \%$ & $83,8 \%$ & $22,0 \%$ & $75,4 \%$ & 0,99 & 0,83 & 0,97 \\
\hline
\end{tabular}

Fuente: elaboración propia a partir de datos del IDESCAT.

Sin duda alguna, y como ya se ha apuntado anteriormente, la explicación de esta distribución territorial de los indicadores se debe a la propia oferta formativa de cada ámbito, puesto que, como se ha comentado, los municipios de mayor tamaño no tan sólo poseen una oferta académica que permite satisfacer la demanda local sino que, incluso, ejerce de polo atractivo respecto de los municipios más pequeños próximos.

\section{La comparativa con los datos del censo de población de 2011}

Realizado este análisis de la evolución de la movilidad durante el periodo comprendido entre los cursos académicos 2011-2012 a 2014-2015 a partir de los datos de los registros administrativos, el segundo de los objetivos principales del presente 
artículo es validar esta fuente mediante la comparación de los resultados obtenidos con los que arroja la fuente tradicional para el estudio de la movilidad: el censo de población.

Sin embargo, la comparativa con los datos procedentes de las dos últimas operaciones censales - 2001 y 2011 - es algo confusa por la propia metodología y terminología que usa el INE en la presentación de los datos en su web, de modo que, como se ha visto anteriormente, hay cinco factores limitadores:

1. En primer lugar, el propio universo de estudio, pues mientras que en el censo de 2001 la información se refiere únicamente a la población de 16 años y más (hecho que prácticamente limita la comparación entre aquellas personas que cursan estudios universitarios), en el de 2011 se recoge información de la población de 3 y más años.

2. En segundo lugar, en esta última operación censal se incluyen categorías que deben por no coincidir con la tipología utilizada por el IDESCAT. En concreto, la correspondencia entre las categorías recogidas en el censo de 2011 y las del organismo estadístico catalán se muestran en el cuadro 4.

3. El cuestionario censal ofrece la posibilidad que la respuesta a la pregunta sobre los estudios en curso sea múltiple, de modo que pueden seleccionarse hasta tres opciones distintas.

4. En cuartolugar, la falta de datos desagregados territorialmente limitan la comparabilidad entre ambas fuentes al conjunto del territorio catalán, no siendo posible reproducir para los años censales indicadores municipales como el de autocontención o de autosuficiencia.

5. Finalmente, un hecho menor es el relativo a la fecha de referencia de los datos en una y otra fuente: así, el censo de población de 2011 tiene como fecha de referencia el 1 de noviembre de aquel año, de modo que la comparación deberá hacerse, necesariamente, con los registros administrativos correspondientes al curso 2011-2012.

Cuadro 5. Tipos de enseñanza recogidos en el censo de la población de 2011

\begin{tabular}{|c|c|}
\hline Tipo & Enseñanza \\
\hline \multirow{5}{*}{$\begin{array}{l}\text { No } \\
\text { universitaria }\end{array}$} & ESO, Educación secundaria para adultos \\
\hline & Programas de Cualificación Profesional Inicial \\
\hline & Bachillerato \\
\hline & Grado Medio de FP, de Artes Plásticas y Diseño y de Enseñanzas Deportivas \\
\hline & Grado Superior de FP, de Artes Plásticas y Diseño y de Enseñanzas Deportivas \\
\hline \multirow{4}{*}{ Universitaria } & Diplomatura universitaria, Arquitectura Técnica, Ingeniería Técnica \\
\hline & Estudios de Grado Universitarios y de Enseñanzas Artísticas y equivalentes \\
\hline & Licenciatura, Arquitectura, Ingeniería o equivalente \\
\hline & Máster oficial universitario, Especialidades Médicas o análogos \\
\hline \multirow{6}{*}{$\begin{array}{l}\text { No incluidos } \\
\text { en los registros } \\
\text { administrativos } \\
\text { de la Generalitat } \\
\text { de Catalunya }\end{array}$} & Enseñanzas de Escuelas Oficiales de Idiomas \\
\hline & Enseñanzas Profesionales de Música y Danza \\
\hline & Otros cursos de educación reglada (Enseñanzas iniciales para adultos...) \\
\hline & Cursos de formación de los Servicios Públicos de Empleo \\
\hline & Otros cursos de formación no reglados \\
\hline & Doctorado \\
\hline
\end{tabular}

Fuente: elaboración propia a partir de datos del IDESCAT. 
Hechas todas estas consideraciones previas, los datos censales parecen validar las cifras procedentes de los registros administrativos de la Generalitat de Catalunya: ${ }^{30}$ así, según el censo de 2011 , la cifra de personas residentes en Catalunya (de 3 años y más) que estaba realizando algún tipo de estudios era de 1.257.516, de los cuales 1.106 .476 correspondían a estudios no universitarios y 151.040 a estudios de grado superior, cifras que son entre un 4 y un $6 \%$ inferiores a las procedentes de los registros administrativos (cuadro 5), cifras asumibles que pueden atribuirse, probablemente, a un error en el muestreo de la operación censal.

Donde mayores son las discrepancias entre ambas fuentes es en los datos de os puestos de estudio localizados: si bien entre los no universitarios las cifras se asemejan a los de los alumnos residentes (con una diferencia del 6,35 \%), en el caso de los alumnos universitarios, las discrepancias se disparan hasta el 15,29\%. La explicación a este hecho puede deberse a la combinación de hasta tres factores: en primer lugar, al hecho que mientras en los datos censales la unidad de medida son las personas, en los registros de la Generalitat la base son las matrículas, de modo que especialmente en el caso de los estudios universitarios la diferencia observada puede deberse a aquellas personas que cursan más de un estudio universitario a la vez (dobles titulaciones, simultaneidad de estudios, etc.), hecho que probablemente no pasa con tanta intensidad en el resto de niveles educativos. En segundo lugar, parte de la diferencia de cerca de 30.000 estudiantes universitarios puede deberse a la presencia de alumnos que, a pesar de residir en el extranjero ( $y$, por tanto, no contabilizados en el censo español de población) cursan estudios en Cataluña. Finalmente, en tercer lugar, y aunque explícitamente así se hace constar en la metodología publicada por el IDESCAT, no podemos descartar que haya algún error de codificación entre los estudiantes de doctorado, de modo que alguno de ellos pueda estar incluido en las estadística que facilita el organismo autonómico.

Cuadro 6. Comparación de los alumnos residentes y los puestos de estudio localizados en Cataluña según el censo de 2011 y los registros administrativos del curso 2011-2012

\begin{tabular}{|c|c|c|c|c|c|}
\hline \multirow{2}{*}{\multicolumn{2}{|c|}{ Variable }} & \multirow{2}{*}{$\begin{array}{c}\text { Censo } 2011 \\
\text { (a) }\end{array}$} & \multirow{2}{*}{$\begin{array}{l}\text { Registro } \\
\text { curso 2011- } \\
2012 \text { (b) }\end{array}$} & \multicolumn{2}{|c|}{ Diferencia (b - a) } \\
\hline & & & & Absoluta & Relativa \\
\hline \multirow{3}{*}{$\begin{array}{l}\text { Alumnos residentes } \\
\text { (AR) }\end{array}$} & No universitarios & 1.106 .476 & 1.180 .484 & 74.008 & $6,27 \%$ \\
\hline & Universitarios & 151.040 & 157.735 & 6.695 & $4,24 \%$ \\
\hline & Total & 1.257 .516 & 1.338 .219 & 80.703 & $6,03 \%$ \\
\hline \multirow{3}{*}{$\begin{array}{l}\text { Puestos de estudio } \\
\text { localizados (PEL) }\end{array}$} & No universitarios & 1.109 .173 & 1.184 .395 & 75.222 & $6,35 \%$ \\
\hline & Universitarios & 163.554 & 193.076 & 29.522 & $15,29 \%$ \\
\hline & Total & 1.272 .727 & 1.377 .471 & 104.744 & $7,60 \%$ \\
\hline
\end{tabular}

Fuente: elaboración propia a partir de datos del IDESCAT.

30 El autor agradece la colaboración de Marc Ajenjo, investigador del Centre d'Estudis Demogràfics, en el tratamiento y el análisis estadístico del fichero de microdatos del Censo de Población de 2011. 


\section{A modo de conclusiones}

La metodología ensayada en el censo de población de 2001 e implementada completamente en el de 201 1, por la cual se implanta en España una operación mixta basada en la combinación del trabajo de campo con el aprovechamiento de los registros administrativos existentes, ha significado una pérdida de información territorial que es especialmente grave en el estudio de la movilidad habitual (por motivos de trabajo o estudio) de la población. Como puede deducirse, el principal inconveniente es que, al proceder la mayoría de los datos de una encuesta realizada a una porción pequeña de la población española, se pierde necesariamente significación y representatividad estadística para los ámbitos territoriales más pequeños, de modo que el grado de desagregación de los datos disponibles ha de ser, necesariamente, menor. Así, en el caso de la movilidad habitual de la población, se pierde la posibilidad de reproducir la matriz de orígenes y destinos de la movilidad habitual, herramienta básica para, por ejemplo, delimitar áreas funcionales o regiones metropolitanas.

La adopción de esta particular metodología de elaboración del censo de población - por otro lado, cabe decir que implementada igualmente en muchos otros países del ámbito europeo-, resta, pues, información, pero a la vez apunta hacia cual debe ser la solución al problema que aquí se plantea: el uso de fuentes alternativas, como son los registros administrativos, para el estudio de determinadas temáticas.

Así, en el caso concreto de la movilidad por motivos de trabajo, cabría esperar que el cruce de determinada información -básicamente el lugar de residencia y el lugar de trabajo--, sin duda disponible en la Tesorería General de la Seguridad Social o en otros organismos dependientes del Ministerio de Empleo y Seguridad Social, habría de permitir conocer el comportamiento territorial de los trabajadores españoles.

Mientras que por el momento no conocemos ninguna experiencia en este sentido, sí es interesante destacar la labor realizada por el IDESCAT catalán para el conocimiento de la movilidad por motivos de estudios a partir de los datos de matriculación del alumnado que cursa algún tipo de estudios oficiales en Catalunya disponibles en las consejerías de educación y de educación y conocimiento de la Generalitat de Catalunya. Así, mediante estas fuentes podemos conocer la movilidad de la población estudiante (a partir de los tres años de edad) para cada uno de los municipios catalanes, en función del tipo de formación que se recibe (segundo ciclo de educación infantil, educación primaria, educación secundaria obligatoria, bachillerato, ciclos formativos de grado medio, ciclos formativos de grado superior y estudios universitarios), el sexo y la edad a partir del curso académico 201 1-2012 y con una periodicidad anual.

Dicha explotación permite conocer, como se ha demostrado en el presente trabajo, la evolución de los «protagonistas» de la movilidad (los alumnos residentes y los puestos de estudio localizados) a escala municipal así como el cálculo de indicadores clásicos de movilidad como la autocontención (calculada sobre los alumnos residentes) y la autosuficiencia (en relación a los puestos de estudio localizados) 
u otros de tipo complementario como el índice de especialización funcional (que pone en relación ambos valores).

En relación a estos aspectos, y aunque el plazo temporal abarcado por esta nueva fuente es todavía muy corto, el trabajo ha permitido identificar algunas tendencias interesantes en relación a la movilidad por motivo de estudios en Catalunya y sus protagonistas. Un primer dato es el progresivo aumento de la población de 3 o más años que cursa algún tipo de estudio, hasta situarse en algo más de 1,2 millones de personas durante el curso 2014-2015. Sin embargo, cabe indicarse que se trata, con toda probabilidad, de una situación transitoria y que esconde un comportamiento diferenciado entre los dos colectivos analizados: mientras que la cifra de estudiantes universitarios crece con motivo del ligero aumento de la movilidad que se produjo durante la primera mitad de la primera década del siglo XXI, la población universitaria tiene a estabilizarse cuando no a disminuir por la llegada a la mayoría de edad de las generaciones "vacías» nacidas durante la crisis de natalidad en nuestro país durante la década de los años noventa del siglo pasado. En relación al aumento de población residente, se ha producido un incremento en el número de puestos de estudios de estudio localizados en Cataluña.

Centrándonos en la movilidad derivada de la diferente localización en el territorio de la población estudiante y de los centros educativos, lo primero que hay que destacar es que Catalunya en su conjunto actúa como un sistema muy cerrado, con una práctica equiparación en el número de ambas variables, hecho que sólo se ve ligeramente matizado en el caso de los estudiantes universitarios, donde la comunidad catalana consigue atraer una media de unos treinta mil personas que, aun no residiendo en Catalunya, cursan sus estudios en alguna de las ocho universidades catalanas analizadas.

Territorialmente, existe una clara diferenciación espacial de la movilidad. Así, las capitales de comarca - con la ciudad de Barcelona al frente- y otros municipios cercanos de su entorno metropolitano más cercano, tienden a presentar unos niveles de autocontención más elevados (superiores al 85\%) que el resto de municipios, donde la falta de oferta formativa ejerce un papel de "expulsión» de su población estudiante. A su vez, los valores del indicador de autosuficiencia en estos municipios reseñados confirman su papel de atracción sobre los territorios más próximos, de manera que su oferta formativa - en volumen y variedad - supera la lógica municipal para responder a una necesidad comarcal, como así lo demuestra un índice de especialización que muestra claramente el mayor número de puestos de estudio localizados en relación a su población residente. Esta misma tendencia se confirma si, en lugar de analizar municipio a municipio, el estudio se hace por franjas poblacionales: existe una relación directa entre el tamaño del municipio y el indicador de autocontención y una relación inversa con el de autosuficiencia, al mismo tiempo que son únicamente los municipios mayores de 25.000 habitantes los que presentan un «excedente» de puestos de estudio en relación a su población residente.

Dando respuesta a otro de los objetivos planteados, el análisis comparativo rea- 
lizado respecto del censo de 2011 , con todas las dificultades técnicas y conceptuales que este ejercicio ha conllevado, confirma la bondad de la nueva fuente para el estudio de la movilidad por estudios en Catalunya. Sin embargo, no todo son buenas noticias. Así, hay que señalar, por un lado, que, desgraciadamente, la información disponible en la web del IDESCAT no permite reconstruir la citada matriz de orígenes y destinos de la movilidad, aunque cabe suponer que el organismo estadístico sí que dispone de esta información y que, bajo demanda específica, puede ser analizada. Por otro lado, la propia naturaleza y titularidad de los datos implica ciertas limitaciones: al elaborarse a partir de los datos de matriculación del alumnado en los centros educativos catalanes, la información disponible contempla la totalidad de los puestos de estudio localizados en Catalunya (con independencia de si quien los ocupa reside o no en dicha comunidad autónoma), mientras que se pierde información para aquellos alumnos catalanes que cursan sus estudios en otro ámbito territorial. Ello implica, pues, que mientras el cálculo de la autosuficiencia para el conjunto de Catalunya no plantea problemas, el de la autocontención para la totalidad de este ámbito esté sobrevalorado: por definición, al no considerar los movimientos «de salida» hacia otras destinos no catalanes, la autocontención autonómica de la población estudiante catalana es del 100\%, Finalmente, un inconveniente menor radica en el hecho que hay un número, reducido eso sí, de alumnos cuyo lugar de residencia se desconoce, con la duda consiguiente de si deben incluirse o no dentro del colectivo que reside en un ámbito distinto al de estudio.

Cabe esperar que en un futuro próximo estas limitaciones actuales puedan ser superadas, a la vez que desde aquí hay que animar al IDESCAT y al resto de organismos estadísticos de nuestro país a seguir explorando nuevas explotaciones de los registros administrativos, especialmente de aquellos que han de permitir conocer, con la periodicidad que se crea oportuna (pero sin duda con una frecuencia mayor que la decenal marcada por el intervalo de tiempo intercensal), la movilidad por motivos de trabajo, variable clave para entender las relaciones espacio-funcionales entre los territorios, a todas las escalas, de nuestro país.

\section{Bibliografía}

AJENJO, M. Evolució i característiques de la mobilitat habitual per treball a Catalunya (1986-2001). L'accessibilitat com a variable intermèdia. Tesis doctoral dirigida por Enric Mendizábal Riera. Bellaterra: Universitat Autònoma de Barcelona. 2005. 567 p.

AJENJO, M. «La mobilitat habitual per treball a Catalunya. Evolució recent ( 19862006) i característiques demogràfiques». Treballs de la Societat Catalana de Geografia, 2010, no69, p. 11-37.

AJENJO, M.; ALBERICH, J.; MEDINA, A. J. Mobilitat habitual i espais de vida a Espanya. Una aproximació a partir del cens de 2001. 2006. Informe elaborado por el Centre d'Estudis Demogràfics por encargo de la Fundació Abertis. 
ALBERICH, J. La vinculació territorial de la població a Catalunya. Una aproximació a partir del cens de 2001. Tesis doctoral dirigida por Marc Ajenjo Cosp. Bellaterra: Universitat Autònoma de Barcelona. 2007. 444 p.

ALBERICH, J. «La mobilitat quotidiana al Camp de Tarragona». Papers de la Regió Metropolitana de Barcelona, 2008, nº 48, p. 46-63.

ALBERICH, J. «Una revisión crítica al concepto de población vinculada según el censo de población de 2001. Una aplicación a Catalunya». In PONS, J. J., MONTORO, C.; LÓPEZ, D. y BARCENILLA, M. C. (ed.). Territorio y movilidad interior de la población en España. Pamplona: Universidad de Navarra, 2009, p. 201-208.

CARRERAS, J. M.; OTERO, M.; RUIZ, E. «Aglomeracions urbanes europeas». Papers de la regió metropolitana de Barcelona, 2009, nº 50, p. 1-246.

CASTAÑER, M.; VICENTE, J.; COMAS, E.; BOIX, G. «Assaig de definició de l'àrea urbana de Girona». Documents d'Anàlisi Geogràfica, 1998, nº 33, p. 81-90.

CASTAÑER, M.; GUTIÉRREZ, O.; VICENTE, J. «Mobilitat laboral, àrees de cohesió i àrees de planificació a Catalunya». Treballs de la Societat Catalana de Geografia, 2009, no 67-68, p. 61-86.

CLUSA, J. La dinàmica metropolitana 1981-1993. Població, habitatge, mercat de treball, mobilitat obligada i mercat immobiliari per sistemes urbans i districtes. Barcelona: Mancomunitat de Municipis de l'Àrea Metropolitana de Barcelona, 1993.

ESTEBAN NOGUERA, J. «El fet metropolità». Papers de la regió metropolitana de Barcelona, 1991, nº 6, p. 16-31.

ESTEBAN QUINTANA, M. «Distribució geogràfica de la mobilitat per treball a la regió metropolitana de Barcelona». Revista Económica de Cataluña, 1989, no 10, p. 98-108.

FERIA, J. M. (2014): «El censo de 2011 en el marco de la experiencia censal en España». [Comunicación presentada en el seminario «Impacto de la metodología del nuevo Censo de Población y Vivienda 2011 en las investigaciones socio-urbanísticas». [En línea] <http://www2.aq.upm.es/Departamentos/Urbanismo/blogs/re-hab/ files/2014/05/20140326_JMFeria.pdf> [8 de febrero de 2016].

GANAU, J. «El sistema urbà de Lleida: definició, estructura i dinàmiques recents». Documents d'Anàlisi Geogràfica, 1998, no 33, p. 91-106.

GANAU, J. «El canvi urbà a Catalunya. Anàlisi dels fluxos residencials i laborals a 
l'àrea de Lleida (1986-1996)». Revista Catalana de Sociologia, 2001, nº 14, p. 57-73.

INSTITUTO NACIONAL DE ESTADÍSTICA. Evaluación de la calidad de los datos del Censo de Población 2001. [En línea] s. f. <http://www.ine.es/censo2001/EvaluacionCenso2001VFinal3.pdf> [ 18 de diciembre de 2015].

INSTITUTO NACIONAL DE ESTADÍSTICA Censos de población y viviendas 2001. Proyecto. [En línea]. 2001.<http://www.ine.es/censo2001/index.html> [ 14 de diciembre de 2015].

INSTITUTO NACIONAL DE ESTADÍSTICA. Proyecto de los Censos Demográficos 2011. [En línea]. 201 la.<http://www.ine.es/censos2011/censos2011_proyecto.pdf> [18 de diciembre de 2015].

INSTITUTO NACIONAL DE ESTADÍSTICA. Metodología de cálculo de las cifras de población censal. 2011b. <http://www.ine.es/censos2011/censos2011_meto_calculo.pdf> [18 de diciembre de 2015]

MIRALLES-GUASCH, C.; DOMENE, E. «Sustainable transport challenges in a suburban university: The case of the Autonomous University of Barcelona». Transport Policy, 2010, no 17, p. 454-463.

MIRALLES-GUASCH, C.; MARTÍNEZ, M.; MARQUET, O. «On user perception of private transport in Barcelona Metropolitan area: an experience in an academic suburban space». Journal of Transport Geography, 2014, n 36, p. 24-31.

MÓDENES, J. A. Movilidad espacial: uso temporal del territorio y poblaciones vinculadas. In PONS, J. J., MONTORO, C.; LÓPEZ, D. y BARCENILLA, M. C. (ed.). Territorio y movilidad interior de la población en España. Pamplona: Universidad de Navarra, 2009, p. 171-185.

NUNES, J. «Aproximació a l'estructura de l'àrea metropolitana de Barcelona: les estructures d'intensitat diària». Documents d'Anàlisi Geogràfica, 1986, nº 8-9, p. 71-90.

ORGANIZACIÓN DE LAS NACIONES UNIDAS. Handbook of population census methods. Volum 1: General aspects of a population census. Nova York: Oficina de Estadística de las Naciones Unidas, 1958.

ROCA, J. La delimitació de l'Àrea Metropolitana de Barcelona. Barcelona: Centre de Política del Sòl i Valoracions, Universitat Politècnica de Catalunya, 1997.

ROQUER, S.; BLAY, J. «El censo de población de 2001: análisis y valoración de los 
principales cambios introducidos». Revista de Geografia, 2002, no 1, p. 107-118.

SERRA, J. Mercats de treball a la regió de Barcelona. Delimitació a partir de la mobilitat residència-treball. Revista Económica, 1985, n 76, p. 21-28.

SERRA, J. La ciutat metropolitana. Delimitacions, desconcentracions, desequilibris. Papers de la regió metropolitana de Barcelona, 1991, nº 6, p. 32-51.

VINUESA, J. «De la población de hecho a la población vinculada». Cuadernos Geográficos, 2005, no 36, p. 79-90. 